\title{
Nitric Oxide Is Necessary for Multiple Memory Processes after Learning That a Food Is Inedible in Aplysia
}

\author{
Ayelet Katzoff, Tziona Ben-Gedalya, and Abraham J. Susswein \\ Faculty of Life Sciences, Gonda (Goldschmied) Medical Diagnostic Research Center, Bar Ilan University, \\ Ramat Gan 52 900, Israel
}

Nitric oxide (NO) signaling was inhibited via $N \omega$-nitro-L-arginine methyl ester (L-NAME) during and after training Aplysia that a food is inedible. Treating animals with L-NAME 10 min before the start of training blocked the formation of three separable memory processes: (1) short-term, (2) intermediate-term, and (3) long-term memory. The treatment also attenuated, but did not block, a fourth memory process, very short-term memory. L-NAME had little or no effect on feeding behavior per se or on most aspects of the animals' behavior while they were being trained, indicating that the substance did not cause a pervasive modulation or poisoning of many aspects of feeding and other behaviors. Application of L-NAME within 1 min after the training had no effect on short- or long-term memory, indicating that NO

Nitric oxide (NO) is an unconventional transmitter in the nervous systems of many animals (Garthwaite and Boulton, 1995; Jacklet, 1997). NO transmission is associated with memory formation in vertebrates (Böhme et al., 1993; Kendrick et al., 1997) and invertebrates (Müller, 1996). Neurons using NO are found in the neural circuit controlling Aplysia feeding (Jacklet, 1995). This well characterized circuit (Weiss et al., 1986a,b; Susswein and Byrne, 1988; Plummer and Kirk, 1990; Teyke et al., 1990, 1993; Rosen et al., 1991; Morton and Chiel, 1993; Hurwitz and Susswein, 1996; Hurwitz et al., 1997; Susswein et al., 2002) is used as a model for examining the organization and regulation of a complex behavior (Kupfermann et al., 1991). Aplysia feeding is modified by both associative and nonassociative learning (Susswein et al., 1986; Schwarz et al., 1988; Lechner et al., 2000; Brembs et al., 2002). Information on the role of NO transmission in learning and memory in this circuit can be put into a wider context, in which cellular, circuit, and behavioral properties are all accessible.

We have examined the role of NO in an associative learning task having affinities with instrumental learning in higher animals. In this task, Aplysia are stimulated with a food that is too tough to eat. This food elicits bites that lead to food entry into the mouth. The food then elicits swallowing movements, but these are ineffective because the food is too tough. The animals' responses become progressively less vigorous, and they eventually stop responding. The changes in response are specific to the taste and texture of the food. The changes in behavior are dependent on

Received April 30, 2002; revised Aug. 12, 2002; accepted Aug. 14, 2002.

This work was supported by grants from the Israel Science Foundation. We thank the late Irving Kupfermann and Sam Schacher for comments on this manuscript.

Correspondence should be addressed to Dr. Abraham J. Susswein at the above address. E-mail: avy@mail.biu.ac.il.

Copyright ( 2002 Society for Neuroscience $\quad 0270-6474 / 02 / 229581-14 \$ 15.00 / 0$ signaling was not needed during memory consolidation. Treating animals with the NO scavenger 2-phenyl-4,4,5,5-tetramethylimidazdine-1-oxy-3-oxide before training also blocked long-term memory. Memory was not blocked by D-NAME, or by the simultaneous treatment with L-NAME and the NO donor $S$-nitroso- $N$-acetyl-penicillamine, confirming that the effect of L-NAME is attributable to its effect as a competitive inhibitor of L-arginine for NO synthase in the production of NO rather than to possible effects at other sites. These data indicate that NO signaling during training plays a critical role in the formation of multiple memory processes.

Key words: nitric oxide; learning; long-term memory; shortterm memory; intermediate-term memory; feeding; Aplysia the entry of food into the mouth and on the consequent failed attempts to swallow (Susswein et al., 1986; Schwarz et al., 1988). Memory after training is monitored by a maintained decrease in response to the inedible food and by savings in the time to retrain animals (Schwarz et al., 1988, 1991). Four separable memory processes (very short-, short-, intermediate-, and long-term memory) are seen after training. The memory processes can be separated by post-training procedures (Botzer et al., 1998), which block long-term memory but leave short-term memory intact. Memory processes can also be distinguished by a variety of training protocols. Some protocols lead only to long-term memory, with no preceding expression of short- or intermediate-term memory, whereas others produce both short- and long-term memory but not intermediate-term memory (Botzer et al., 1998). The ability to achieve long-term memory in animals that did not first display short-term memory showed that short- and long-term memory are independent, parallel processes. Long-term memory can last for up to 3 weeks (Schwarz et al., 1991).

This research examines the effects on learning and on the various memory processes of blocking NO signaling. Blocking of NO signaling before training had no measurable effect on Aplysia feeding, and during learning with inedible foods, most aspects of the training were normal. However, blocking NO signaling during training attenuated very short-term memory and completely blocked short-, intermediate-, and long-term memories. Blocking of NO signaling immediately after training had no effect on either short- or long-term memory, indicating that NO release only during the training, and not during consolidation, plays a role in memory formation.

\section{MATERIALS AND METHODS}

Animals. Experiments were performed on Aplysia fasciata and Aplysia californica. A. fasciata weighed 50-150 gm and were collected along the Mediterranean coast of Israel. This species is available locally from May 
through August, and experiments performed during this period used them. A. californica weighed 100-150 gm and were purchased from Marine Specimens Unlimited (Pacific Palisades, CA). A. californica was used for experiments when $A$. fasciata were unavailable. The choice of the species used was based on the season during which a particular experiment was performed. Some experiments were repeated using both species, with no differences in results. The species used in each experiment is noted below. Animals were stored five or six to a cage in plastic mesh cages immersed in 13001 tanks of aerated, filtered Mediterranean seawater at $18^{\circ} \mathrm{C}$ with a $12 \mathrm{hr}$ light-dark cycle. The animals were fed one or two times weekly with Ulva lactuca that was gathered along with $A$. fasciata and was stored frozen.

One week before an experiment, animals were separated from one another. They were kept thereafter in individual cages and were fooddeprived. Twenty-four hours before an experiment, they were transferred to 101 experimental aquariums that were maintained at $19-20^{\circ} \mathrm{C}$. Because in $A$. fasciata the presence of a conspecific in the environment is needed for animals to learn that a food is inedible (Schwarz and Susswein, 1992), a second Aplysia was always transferred to the experimental aquarium along with the experimental animal. The second animal was maintained behind a partition that was not a barrier to the flow of seawater but that prevented contact between the animals. Because $A$. californica are diurnally active (Kupfermann, 1968) and $A$. fasciata are nocturnal animals (Ziv et al., 1991), experiments on $A$. californica were performed during the light portion of the day, whereas those on $A$. fasciata were done during the dark portion, as described previously (Susswein et al., 1986).

Tests of response to food. A number of experiments examined the animals' ability to respond to food, independent of learning. To test the response of animals to a pure chemical stimulus that evokes feeding, a seaweed extract was prepared by soaking Ulva in 20 times its weight of seawater and then homogenizing this mixture for $20 \mathrm{~min}$. The mixture was then filtered, and $15 \mathrm{ml}$ of the fluid was placed in a 51 aerated experimental chamber containing an animal. The animal had been transferred to the container $12 \mathrm{hr}$ before the start of the experiment. Other experiments examined the response to ad libitum access to food as well as to small pieces or strips of seaweed. Techniques for examining the response to food were as described previously (Susswein et al., 1976; Rosen et al., 1989; Blumberg and Susswein, 1998; Blumberg et al., 1998).

Training procedure. As in previous studies (Schwarz and Susswein, 1986; Susswein et al., 1986; Schwarz et al., 1988, 1991; Botzer et al., 1998), training began by touching a small piece of Ulva wrapped in plastic net to the rhinophores of animals. Aplysia respond to this stimulus by lifting the head and centering food on the lips. Food on the lips initiates a biting response, which leads to entry of food into the buccal cavity. Food in the buccal cavity leads to swallowing responses. However, because netted food physically cannot be swallowed, it becomes lodged in the buccal cavity, where it produces repetitive failed swallowing responses. Food eventually leaves the buccal cavity. The netted food continues to stimulate the lips, producing further biting responses, which again lead to failed swallows. As training proceeds, many responses fail to lead to entry of food into the buccal cavity. When food enters the buccal cavity, it stays within the cavity for progressively shorter periods, eliciting fewer attempted swallowing responses. Finally, animals stop responding to the netted food. The criterion for cessation of responsiveness was 3 min without food entering the mouth (Botzer et al., 1998). In all experiments, biting responses and entry and exit of food into and from the buccal cavity were observed visually, and occurrences were noted by pressing the appropriate button of a three-button mouse connected to a computer. A computer program noted the time that a mouse button was pressed. In addition, swallowing responses that were felt by the experimenter as an inward pull on the netted food were also noted.

Memory is shown by testing the animals in a procedure that is identical to that in the initial training. Memory is displayed by a decrease in the responsiveness of the animals at the start of training and by a reduction in the time needed for the animals to stop responding to the food. The measure of responsiveness to food used in this and previous studies is the time spent by food in the buccal cavity during the first $5 \mathrm{~min}$ of a session (Susswein et al., 1986; Botzer et al., 1998).

All experiments testing intermediate- and long-term memory were performed using a blind procedure, in which naive animals, seawatertreated animals, or both were tested along with the experimental animals.

Drugs and drug treatments. NO signaling was blocked with $N \omega$-nitroL-arginine methyl ester (L-NAME; concentration, $100 \mathrm{mg} / \mathrm{kg}$ ), an inhibitor of nitric oxide synthase (NOS). This was delivered by preparing a solution of $10 \mathrm{mg} / \mathrm{ml}$ in artificial seawater (ASW) and injecting animals with a volume that was appropriate to the animal's weight. Most animals weighted $\sim 100 \mathrm{gm}$, so $1 \mathrm{ml}$ was injected. The composition of the artificial seawater was (in $\mathrm{mM}$ ): $\mathrm{NaCl}, 460 ; \mathrm{KCl}, 10 ; \mathrm{CaCl}_{2}, 11 ; \mathrm{MgCl}_{2}, 55$; and $\mathrm{NaHCO}_{3}$, 5. In some experiments, D-NAME, at a concentration identical to that of L-NAME, was injected into animals as a control for the possible nonspecific effects of L-NAME. In one experiment, animals were injected with 2-phenyl-4,4,5,5-tetramethyl-imidazdine-1-oxy-3oxide (PTIO), an NO scavenger, at a concentration of $0.025 \mathrm{~mm}$. Animals of $\sim 100 \mathrm{gm}$ were then injected with $1 \mathrm{ml}$ of this solution. In one experiment, the NO donor $S$-nitroso- $N$-acetyl-penicillamine (SNAP; 1 $\mathrm{mM}$ ) was injected immediately after the L-NAME treatment, Animals were injected with a solution of $0.2 \mathrm{mg} / \mathrm{ml}$ prepared in ASW. Animals were injected with these substances either $10 \mathrm{~min}$ before training or immediately (within $1 \mathrm{~min}$ ) after training, as was needed for the experimental procedure.

Statistics. Many experiments examined the effects of a drug on memory after training. The presence of memory was measured by using paired $t$ tests that compared the behavior before and after training. In addition, the percentage of change in response for experimental animals was compared with that of seawater-treated controls that were run simultaneously. For each animal, the percentage of change between the training and testing session was calculated, and a $t$ test was used to determine whether there were significant differences between experimental and control groups. For some experiments, data were not available on the parameters of the initial training, and in these experiments, the parameters of the sessions testing memory were compared between experimental and control groups, using $t$ tests.

\section{RESULTS}

\section{L-NAME does not block feeding behavior}

The aim of the study was to determine whether NO signaling has a role in learning that food is inedible or in memory after learning. However, before determining whether inhibiting NO signaling affects learning or memory, it was important to examine whether such inhibition affects feeding behavior per se. Animals (A. fasciata) were allowed $1 \mathrm{hr}$ of ad libitum access to food after 1 week of food deprivation. Animals were observed throughout this hour, and the start and end of all feeding bouts were noted. Previous studies (Ziv et al., 1991) have shown that such observations are accurate to within $\sim 15 \mathrm{sec}$ in judging the start and stop of feeding, and individual bouts of feeding are minutes long. The percentage of time spent feeding was then calculated in animals that were treated with L-NAME 10 min before the start of the observation as well as in control animals that were treated with seawater. There were no obvious differences in the patterning or vigor of feeding movements between animals injected with L-NAME and those injected with seawater. In both groups, 65$70 \%$ of the hour was devoted to feeding, and there was no significant difference in the time devoted to feeding $(p=0.78$; $t_{(11)}=0.29$; two-tailed $t$ test) (Fig. $1 A$ ). These data indicate that L-NAME does not disrupt feeding behavior, although it is possible that L-NAME may cause subtle effects that require a finegrained analysis to discern.

Additional experiments examined the possible effect of L-NAME on a number of different consummatory movements. In one, the ability of food to arouse animals ( $A$. fasciata) was examined. Previous experiments (Kupfermann, 1974; Susswein et al., 1978) have shown that exposure to food arouses Aplysia, so that they become more responsive to food on subsequent exposures. The latency from the first touch of food (the seaweed Ulva) to the head of an animal until it bites the food is a reliable measure of its current arousal state (Susswein et al., 1978). We measured this initial arousal latency in animals that were treated with L-NAME 10 min previously and in control animals that were treated with seawater (Fig. 1B). There was no significant difference in arousal latency between these two groups $\left(p=0.43 ; t_{(16)}=0.82\right.$; two- 


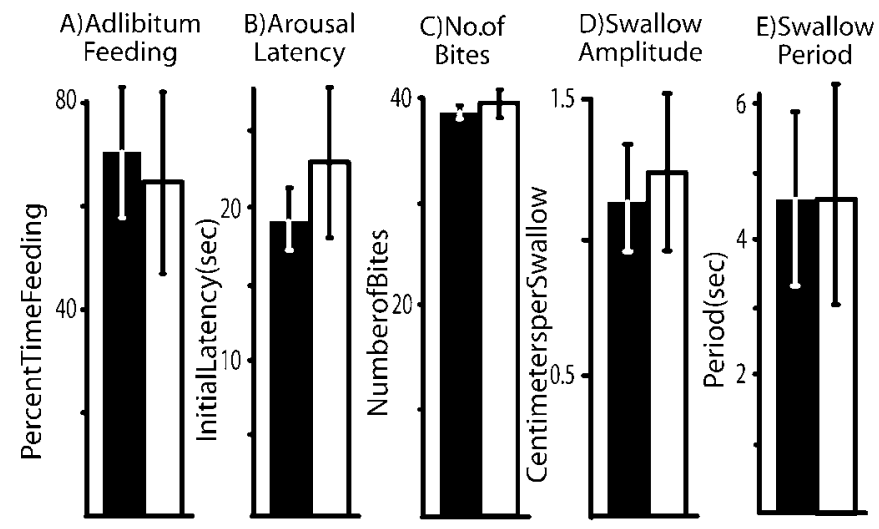

Figure 1. Lack of effects of L-NAME on feeding behavior. Shaded bars, Treated with L-NAME; open bars, treated with seawater. $A$, Percentage of time spent feeding in $1 \mathrm{hr}$ of ad libitum exposure to food $(n=7$ seawater controls; $n=6$ animals treated with L-NAME). $B$, Latency to respond to food touching the lips in previously unaroused animal $(n=7$ seawatertreated animals; $n=11 \mathrm{~L}-\mathrm{NAME}$-treated animals). $C$, Number of bites in a 5 min period in which the lips were stimulated continuously with food $(n=8)$. $D$, Swallow amplitude. $E$, Swallow period $(n=10$ seawatertreated animals; $n=5$ L-NAME-treated animals). In this and in subsequent figures, means and SE are shown.

tailed $t$ test), indicating that L-NAME did not affect the ability of food to arouse animals.

An additional experiment examined the possible effect of L-NAME on biting. Animals (A. californica) were injected with either L-NAME or seawater, and $10 \mathrm{~min}$ later, their lips were stimulated with seaweed for $5 \mathrm{~min}$. Animals were not permitted to consume the food, which was briefly pulled away from the mouth when the animals bit. The number of bites elicited during the 5 min stimulation was counted. Twenty-four hours later, the procedure was repeated, except that animals that had been exposed to L-NAME were injected with seawater and vice versa (Fig. 1C). There was no significant difference in the number of bites when animals were treated with L-NAME or seawater ( $p=$ $0.55 ; t_{(7)}=0.63$; two-tailed paired $t$ test).

An additional experiment examined whether L-NAME affects a second Aplysia consummatory movement, swallowing. Animals were fed strips of food (the seaweed Ulva, which was cut into 6-cm-long $\times 3$-mm-wide strips), which elicited a single bite and a series of swallowing responses. The number of swallows and the time needed to consume the strip were measured in animals that were exposed to either L-NAME or seawater 10 min before being fed. This examination provides information on the swallow amplitude, as measured by the length consumed per swallow, and the swallow frequency, as measured by the interswallow interval (Blumberg et al., 1998). There were no significant differences for either of these parameters between animals exposed to seawater and L-NAME (for swallow amplitude, $p=0.21, t_{(14)}=1.33$; for interswallow interval, $p=0.92, t_{(14)}=0.11$; two-tailed paired $t$ tests). These data indicate that swallowing is not affected by L-NAME (Fig. 1D,E).

In another gastropod, Lymnaea, blocking of NO signaling attenuates or blocks the ability of animals to respond to a purely chemical stimulus that initiates feeding movements (Elphick et al., 1995; Korneev et al., 2002). In contrast, in the experiments above, we found that Aplysia respond well to food, even when NO signaling is blocked. However, in our experiments, the food stimulus touched the animals; therefore, food was sensed via both chemoreceptors and mechanoreceptors (Rosen et al., 1982),
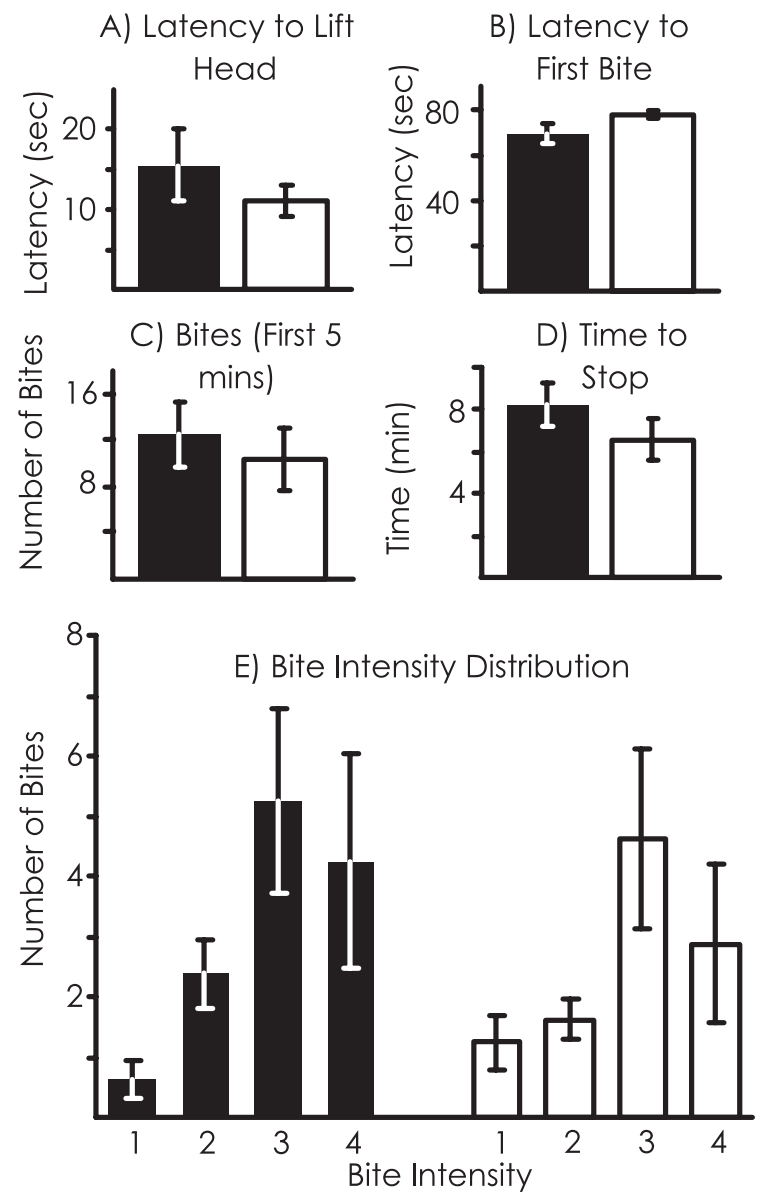

Figure 2. Lack of effects of L-NAME on responses to seaweed extract in $n=8$ seawater-treated and $n=8$ L-NAME-treated animals. Shaded bars, Treated with L-NAME; open bars, treated with seawater. $A$, Latency to lift of the head. There was no significant difference between L-NAME- and seawater-treated animals $\left(p=0.39 ; t_{(14)}=0.88\right)$. $B$, Latency to the first bite. There was no significant difference between L-NAME- and seawatertreated animals $\left(p=0.67 ; t_{(14)}=0.43\right)$. $C$, Number of bites in $5 \mathrm{~min}$ of exposure. There was no significant difference between L-NAME- and seawater-treated animals $\left(p=0.59 ; t_{(14)}=0.55\right)$. $D$, Time to stop responding to the seaweed extract. There was no significant difference between L-NAME- and seawater-treated animals $\left(p=0.39 ; t_{(14)}=0.90\right)$. $E$, Amplitude of each bite elicited by seaweed extract using a four-point scale. There was no significant difference in the relative distribution of the four levels of bite amplitude $\left(p=0.09 ; \chi_{(3)}^{2}=6.42\right)$.

whereas the Lymnaea experiments used a purely chemical stimulus. To determine whether L-NAME blocks Aplysia feeding in response to a purely chemical stimulus, a seaweed extract was placed in a container with an animal (A. californica) that was treated with either L-NAME or seawater, and a number of measures of feeding were observed: (1) the latency from entry of the chemical extract into the water until the lift of the head, as animals assumed the typical feeding posture (Kupfermann, 1974) (Fig. 2A); (2) the latency until the first bite (Fig. 2B); (3) the number of bites performed within the first $5 \mathrm{~min}$ of exposure to the seaweed extract (Fig. 2C); (4) the total time until the Aplysia stopped responding to the seaweed extract (Fig. 2D); cessation of responses (defined as $180 \mathrm{sec}$ without a response) presumably was caused by sensory adaptation to the chemical stimulus (Horn et al., 2001); and (5) the distribution of the amplitude of the responses (Fig. 2E), with the bite amplitude quantified using a four-point scale (Susswein et al., 1976; Rosen et al., 1989). In this 


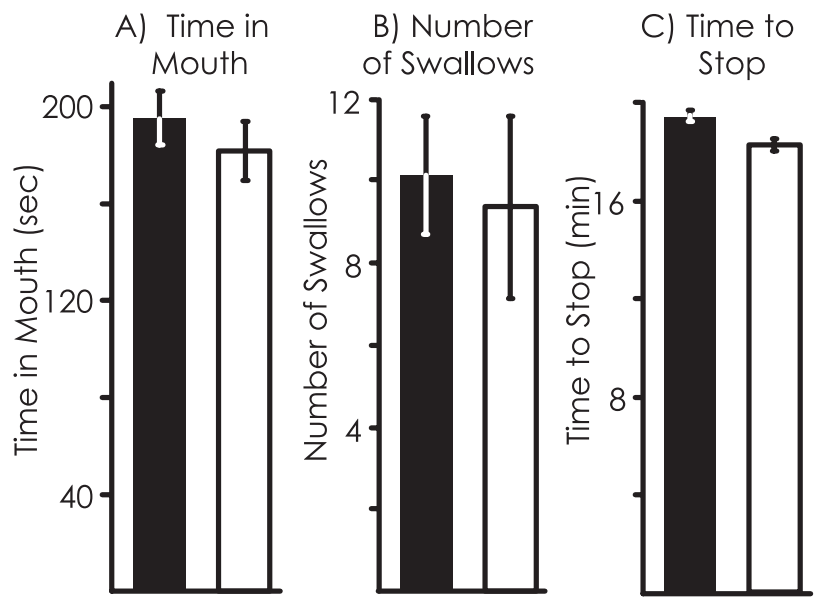

Figure 3. Lack of effects of L-NAME on training. Three parameters of the training were measured. Shaded bars, Treated with L-NAME; open bars, treated with seawater. $A$, Time that food is in the mouth during the first 5 min of training. $B$, Number of attempted swallowing responses performed during the first $5 \mathrm{~min}$ of training. $C$, Length of training needed for the animals to stop responding to the inedible food.

scale, 1 represents the weakest amplitude bite, and 4 is the strongest amplitude. The distribution of the bite amplitudes in animals treated with L-NAME was tested against the distribution of seawater-treated controls. For each animal, the number of bites of each magnitude was counted, and the means and SE of the number of bites of each magnitude were then calculated for all of the L-NAME- and seawater-treated animals. There were no significant differences in any of the parameters of feeding between animals treated with L-NAME and seawater, indicating that the responses to purely chemical stimuli initiating feeding are also not affected by blocking NO signaling.

\section{L-NAME does not block learning that a food is inedible}

Ten minutes after treatment with either L-NAME or seawater, animals (A. fasciata) were stimulated with Ulva that was wrapped in plastic netting, making it inedible. The animals can taste the food through the holes in the net. Animals treated with L-NAME, as well as those treated with seawater, responded readily to the inedible netted food and bit and then attempted to swallow it. After a number of failed attempts to swallow the netted food, it was rejected. The food continued to stimulate the lips, and animals bit and attempted to swallow it again. As the training progressed, animals responded less to the food. The food entered the mouth less frequently, and when it entered, it was rejected earlier. Eventually, animals stopped responding to the netted food. The changes in responses and their cessation are attributed to associative learning (Susswein et al., 1986; Schwarz et al., 1988).

Previous experiments (Susswein et al., 1986) have used the time that food spends in the mouth and the number of swallows elicited by the food as measures of responsiveness to the food. There were no significant differences in these parameters between animals treated with L-NAME or seawater (time in mouth, $p=0.57, t_{(35)}=0.57$; number of swallows, $p=0.76, t_{(23)}=0.31$; two-tailed $t$ tests) during the first 5 min of the training, indicating that the initial response to the inedible food is not affected by L-NAME (Fig. 3A,B).

There was also no significant difference between animals treated with L-NAME or seawater in the time needed to stop responding to the inedible netted food $\left(p=0.56 ; t_{(35)}=0.59\right.$; two-tailed $t$ test), indicating that L-NAME does not affect this parameter of the initial learning that a food is inedible (Fig. 3C).

\section{Block of NO signaling affects short- and long-term memory}

Previous studies have identified a number of separable phases of memory (Botzer et al., 1998). A single training session continued until Aplysia stop responding to food elicits short-term memory, which is maintained for up to $0.5 \mathrm{hr}$, and long-term memory, which is present from 1 to $7 \mathrm{~d}$ after training (Schwarz et al., 1991; Botzer et al., 1998). However, such a training session does not lead to intermediate-term memory, measured from 1 to $12 \mathrm{hr}$ after training. A series of experiments were performed to determine the effects of L-NAME on memory processes that are elicited by a single training session that is continued until animals stop responding to inedible netted food.

\section{L-NAME before training blocks short-term memory}

After training, memory was examined by re-exposing the animals to the same inedible food for a second time. As in previous studies (Botzer et al., 1998; Schwarz et al., 1998), two parameters were used to quantify memory: (1) the initial responsiveness to the food (as measured by the time that food is in the mouth in the first $5 \mathrm{~min}$ ) and (2) the time needed to stop responding to the inedible food. Memory is demonstrated by a decrease in these parameters when animals are retrained, with respect to the values measured in the original training.

The possible effect of L-NAME on short-term memory was examined by treating animals (A. fasciata) with either L-NAME or seawater, training them 10 min later, and then testing the animals $0.5 \mathrm{hr}$ after the end of the initial training (Fig. 4). Previous data (Botzer et al., 1998) have shown that robust shortterm memory is seen at this time. Decreases in both the time to stop responding to food as well as in the time that food spent in the mouth during the first 5 min were seen $0.5 \mathrm{hr}$ after training in seawater-treated control animals, indicating that these animals displayed short-term memory. However, in animals that had been injected with L-NAME before the training, there were no significant differences between the initial training and the test of memory for either the time to stop responding to food or for the time that food was in the mouth during the first $5 \mathrm{~min}$. There were also significant differences in the percentage of changes in responses between the training and testing sessions between animals treated with L-NAME and seawater for both parameters of memory. Values in animals that had been injected with L-NAME were similar to those observed in previously untreated, naive animals that were run as controls in tandem with the previously trained animals. These data indicate that the formation of shortterm memory is blocked in animals injected with L-NAME before training.

\section{Short-term memory is preserved when $L-N A M E$ is injected after training}

Injecting L-NAME before training potentially could interfere with short-term memory formation either during the training period or during the $0.5 \mathrm{hr}$ interval between the training and the test. To differentiate between these possibilities, either L-NAME or seawater was injected into animals (A. californica) immediately (within $1 \mathrm{~min}$ ) after training, and memory was examined $0.5 \mathrm{hr}$ later (Fig. 5). Both the animals injected with L-NAME and those injected with seawater displayed significant decreases in the time to stop responding and in the time that food spent in the mouth 
L-NAME Before Training

A) Time to Stop Responding
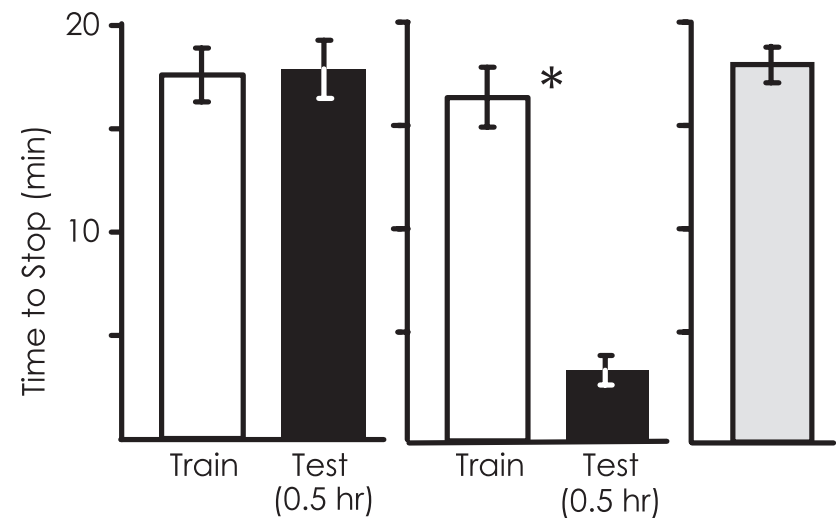

L-NAME

Seawater

Naive

B) Time in the Mouth (first $5 \mathrm{~min}$ )

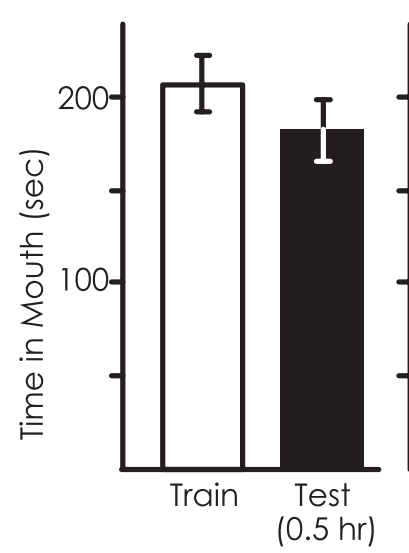

L-NAME

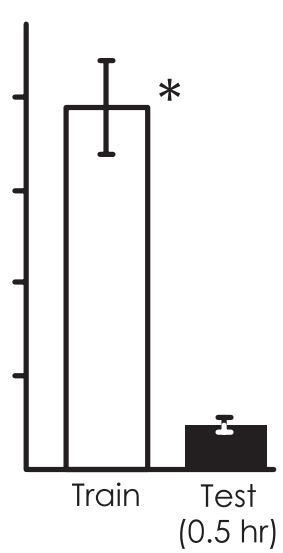

Seawater

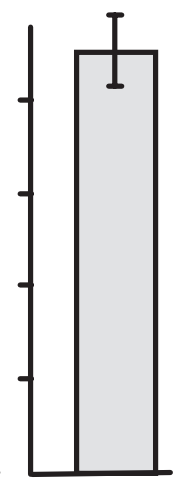

Naive
Figure 4. L-NAME treatment before training blocks short-term memory. Animals were treated before training with L-NAME $(n=7)$ or seawater $(n=6)$. Open bars, Data from the initial training session; shaded bars, data from a second session that measured memory after $30 \mathrm{~min}$. Memory is indicated by a decrease in a value from the first to the second session. Experiments showing a significant decrease in this and in subsequent figures are marked with asterisks. An additional group of previously untreated naive animals (Naive; $n=6$ ) was examined in a blind procedure along with the previously trained animals. $A$, There was a significant decrease in the time for animals to stop responding to inedible food between the training and testing session for the seawater-treated controls $\left(p<0.001 ; t_{(5)}=14.16\right)$ but not for the L-NAME-treated animals $(p=$ $0.340 ; t_{(6)}=1.035 ; 2$-tailed paired $t$ tests). There was also a significant difference in the percentage of change in response between the training and testing session between L-NAME- and seawater-treated animals $\left(p<0.001 ; t_{(11)}>100 ; 2\right.$-tailed $t$ test $) . B$, There was a significant decrease in the time that food was in the mouth during the first 5 min between the two session for the control animals $\left(p<0.001 ; t_{(5)}=7.57\right)$ but not for animals treated with L-NAME $\left(p=0.227 ; t_{(6)}=1.35 ; 2\right.$-tailed paired $t$ tests). In addition, there was a significant difference in the percentage of change in response between training and testing between L-NAME- and seawater-treated animals $\left(p<0.001 ; t_{(11)}=9.48 ;\right.$ 2-tailed $t$ test $)$.

during the first $5 \mathrm{~min}$, indicating that blocking NO synthesis after training does not eliminate short-term memory. In addition, there were no significant differences in the percentage of change in responses between the training and testing sessions between animals treated with seawater and with L-NAME. Thus, the block of memory by L-NAME is the result of the effect of the drug before or during the training and not subsequent to it.
L-NAME After Training

A) Time to Stop Responding

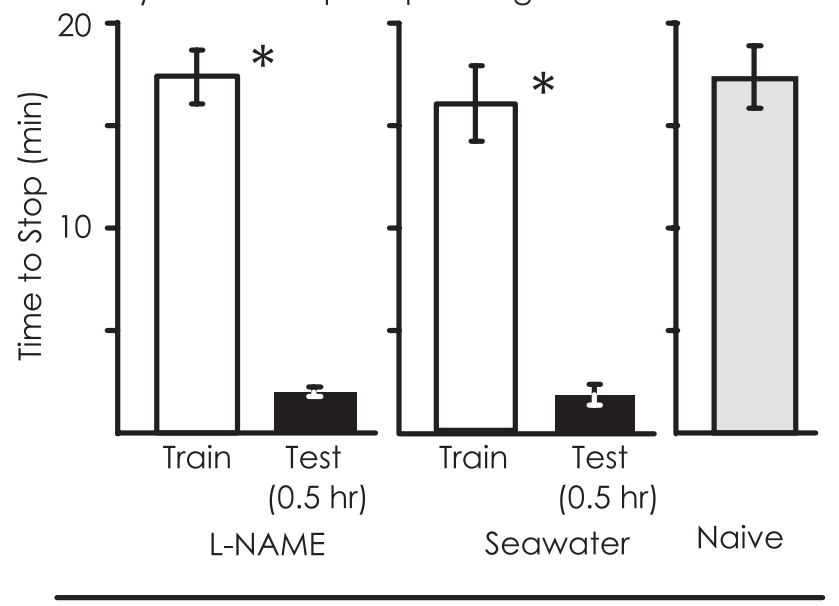

B) Time in the Mouth (first $5 \mathrm{~min}$ )
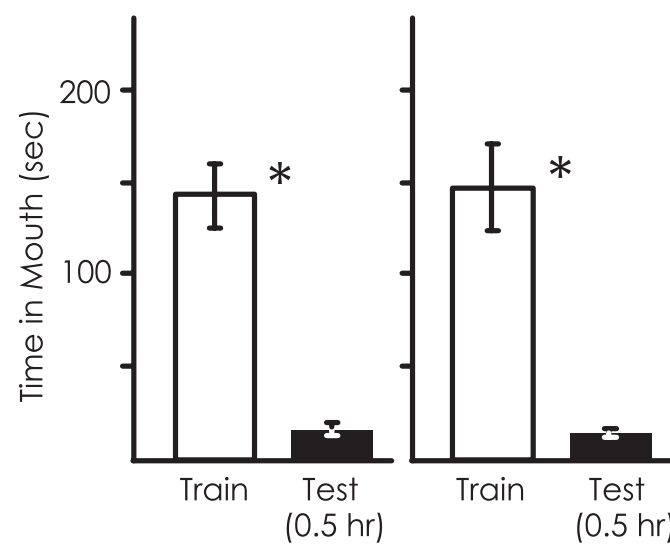

L-NAME

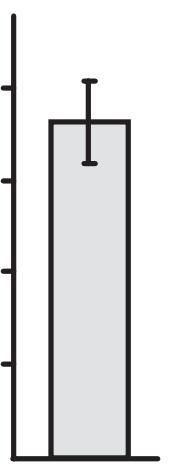

Seawater

Naive

Figure 5. L-NAME treatment immediately after training does not affect short-term memory. The experiment was identical to that in Figure 4, except that animals were treated with L-NAME or seawater immediately after the training. For animals treated with L-NAME, $n=8$; for animals treated with seawater, $n=6$; for naive animals, $n=7$. $A$, There was a significant decrease in the time to stop responding between the training and testing session for the control animals $\left(p<0.001 ; t_{(5)}=8.28\right)$ and for the animals treated with L-NAME $\left(p<0.001 ; t_{(7)}=11.77 ; 2\right.$-tailed paired $t$ tests). In addition, there was no significant difference in the percentage of change in response between the training and testing session between animals treated with L-NAME and with seawater $\left(p=0.94 ; t_{(12)}=0.07\right.$; 2 -tailed $t$ test). $B$, There was a significant decrease in the time that food was within the mouth during the first $5 \mathrm{~min}$ between the training and testing session for animals treated with seawater $\left(p=0.002 ; t_{(5)}=5.74\right)$ and for animals treated with L-NAME $\left(p<0.001 ; t_{(7)}=7.19 ; 2\right.$-tailed paired $t$ tests). In addition, there was no significant difference in the percentage of change in response between the training and testing session $\left(p=0.56 ; t_{(12)}=0.60 ; 2\right.$-tailed $t$ test $)$.

\section{L-NAME before training blocks long-term memory}

Previous studies (Botzer et al., 1998) indicated that short- and long-term memory after learning that a food is inedible are independent processes, because each can be obtained in the absence of the other. The independence of short- and long-term memories raises the possibility that L-NAME specifically blocks short-term but not long-term memory. To examine this possibility, animals (A. fasciata) were treated with either L-NAME or seawater $10 \mathrm{~min}$ before training, and memory was tested $24 \mathrm{hr}$ later (Fig. 6). For the seawater-treated controls, during the test of 


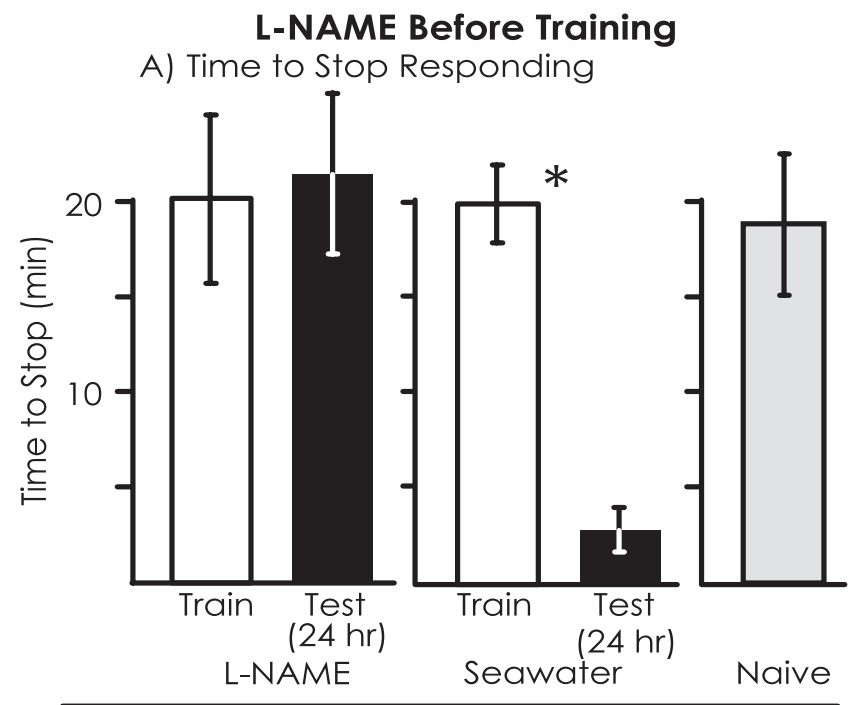

B) Time in the Mouth (first $5 \mathrm{~min}$ )

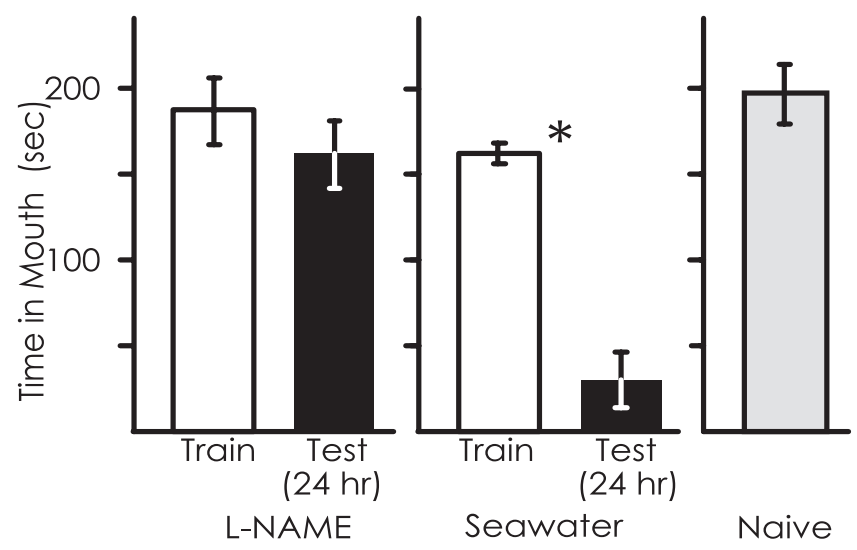

Figure 6. L-NAME treatment before training blocks long-term memory. The experiment was identical to that in Figure 4, except that the test of memory was performed after $24 \mathrm{hr}$. For animals treated with L-NAME, $n=7$; for animals treated with seawater, $n=4$; for naive animals, $n=6$. $A$, There was a significant decrease in the time to stop responding to the inedible food between the training and testing session for the control animals $\left(p<0.001 ; t_{(3)}=25.37\right)$ but not for the L-NAME-treated animals $\left(p=0.32 ; t_{(6)}=1.08 ; 2\right.$-tailed paired $t$ tests). In addition, there was a significant difference in the percentage of change in response between the training and testing session between animals treated with L-NAME and seawater $\left(p<0.001 ; t_{(9)}=10.13 ; 2\right.$-tailed $t$ test $) . B$, There was a significant decrease in the time that food was in the mouth during the first $5 \mathrm{~min}$ from the training and testing session for the control animals $\left(p=0.005 ; t_{(3)}=\right.$ 7.19) but not for the L-NAME-treated animals $\left(p=0.33 ; t_{(6)}=1.06\right.$; 2-tailed paired $t$ tests). In addition, there was a significant difference between L-NAME- and seawater-treated animals in the percentage of change in response from the training to the testing session $(p=0.002$; $t_{(9)}=4.14 ; 2$-tailed $t$ test).

memory there were significant decreases in both the time to stop responding to food and in the time that food was in the mouth during the first $5 \mathrm{~min}$ with respect to the values seen during the initial training. However, there were no significant differences between the training and testing sessions in animals that had been treated with L-NAME before the training. There were also significant differences between animals treated with L-NAME and with seawater in the percentage of changes in response between the training and testing sessions for both the time to stop and for the time spent in the mouth. Values during the $24 \mathrm{hr}$ test in animals that had been treated with L-NAME were similar to those observed in naive animals that were run as controls in tandem with the previously trained animals. These data indicate that the formation of long-term memory is blocked in animals injected with L-NAME before training.

\section{Long-term memory is preserved when $L-N A M E$ is injected after training}

The inhibition of long-term memory by L-NAME could be explained by effects that occur after the training, during the period of memory consolidation. To test this possibility, animals $(A$. fasciata) were treated with either L-NAME or seawater immediately after training, and memory was tested $24 \mathrm{hr}$ later (Fig. 7). Both the animals treated with L-NAME and those treated with seawater displayed significant decreases between the training and testing sessions in the time to stop responding to food and in the time that food spent in the mouth during the first $5 \mathrm{~min}$, indicating that blocking NO synthesis after training does not eliminate long-term memory. There were also no significant differences in the percentage of change in response between the training and testing sessions between animals treated with L-NAME and seawater for both parameters of memory.

\section{Lip stimulation alone is not sufficient to establish long- term memory}

Previous studies have shown that stimulation of the lips with food is not sufficient to cause long-term changes in feeding behavior. Long-term memory also requires food entry into the mouth and the subsequent failure of swallowing responses to convey the food into the gut. The experience of food in the mouth and failed swallows must be temporally associated with the lip stimulation (Susswein et al., 1986). An additional experiment was performed to verify the previous finding that long-term memory requires the temporal association of exposure to food with the subsequent entry of food into the mouth and the failure to swallow the food. This experiment also examined the possible effect of L-NAME on the need for food entry into the mouth on long-term memory.

Animals (A. californica) were treated with either L-NAME or seawater. Half of the L-NAME-treated animals and half of the seawater-treated animals were trained with inedible food until they stopped responding. In the other half, the lips were stimulated with netted food, but the food was not permitted to enter the mouth. Animals that were treated with lip stimulation were yoked to the animals that received normal training with the food entering the mouth; in each stimulated animal, the lip stimulus was continued for a period that was yoked and was therefore identical to that required for cessation of responses in a matched experimental animal. Thus, the duration of the lip stimulation was determined by the time to stop in the trained animal; therefore, the means and SD for the trained and stimulated animals are the same. The yoked procedure was performed for both L-NAMEand seawater-treated animals. Twenty-four hours after training or lip stimulation, all of the animals were tested in a blind procedure, with inedible food that entered the mouth and elicited failed swallows, to test long-term memory (Fig. 8).

For animals treated with seawater, significant differences were observed between the animals that had been trained with food entering the mouth and those in which the lips alone were stimulated for both the time to stop responding to food as well as for the time that food was in the mouth during the first 5 min of the test. For the animals that had received lip stimulation alone, 


\section{L-NAME After Training}

A) Time to Stop Responding

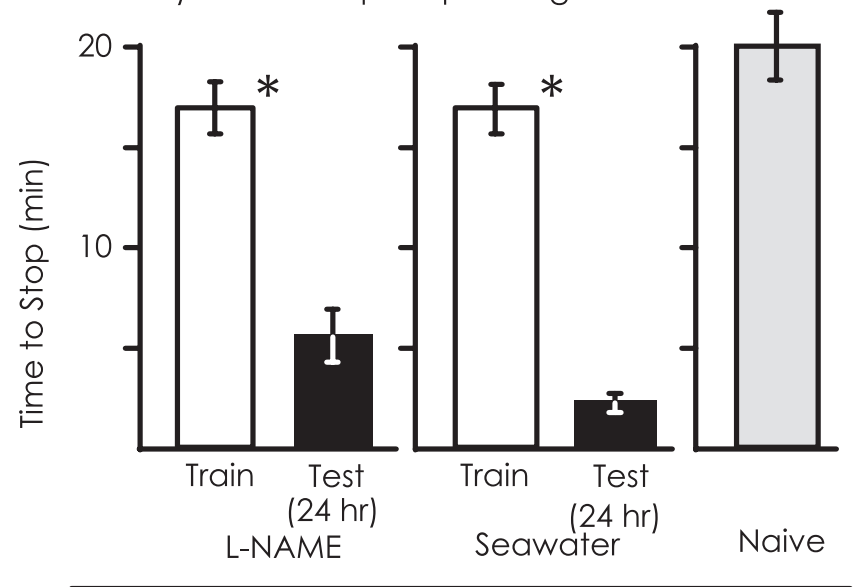

B) Time in the Mouth (first 5 min)

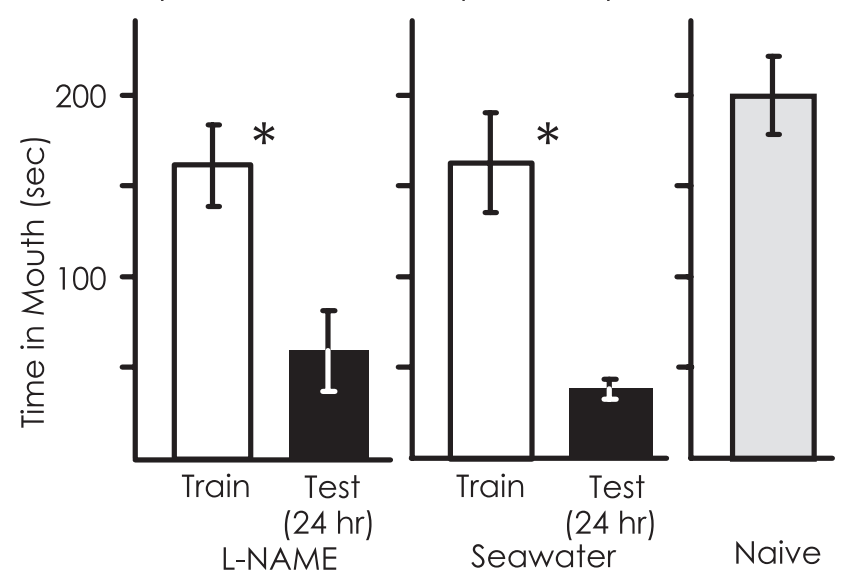

Figure 7. L-NAME treatment immediately after training does not affect long-term memory. The experiment was identical to that in Figure 6, except that animals were treated with L-NAME or seawater immediately after the training rather than preceding it. For animals treated with L-NAME, $n=7$; for animals treated with seawater, $n=5$; for naive animals, $n=5$. $A$, There was a significant decrease in the time to stop responding to the inedible food between the training and testing session for the control animals $\left(p=0.002 ; t_{(4)}=12.13\right)$ and for the L-NAMEtreated animals ( $p=0.001 ; t_{(6)}=5.80 ; 2$-tailed paired $t$ tests). In addition, there was no significant difference between these groups in the percentage of change in response from the training and testing session $(p=0.11$; $t_{(10)}=1.77$; 2-tailed $t$ test). $B$, There was a significant decrease in the time that food was within the mouth during the first 5 min between the training and testing session for the control animals $\left(p=0.013 ; t_{(4)}=4.22\right)$ as well as for the L-NAME-treated animals $\left(p=0.019 ; t_{(6)}=3.16 ; 2\right.$-tailed paired $t$ tests). In addition, there was no significant difference in the percentage of change in response between the training and testing session $\left(p=0.52 ; t_{(10)}=0.67 ; 2\right.$-tailed $t$ test $)$.

values were comparable with those during the initial training with inedible food entering the mouth. In contrast, there were no significant differences in L-NAME-treated animals between those that had been trained previously with food entering the mouth and with food stimulating the lips. Values in both groups were comparable with those in the initial training sessions. These findings confirm that food must enter the mouth and initiate failed swallowing responses to produce long-term memory, and this requirement is not affected in animals treated with L-NAME.
A) Time to Stop Responding

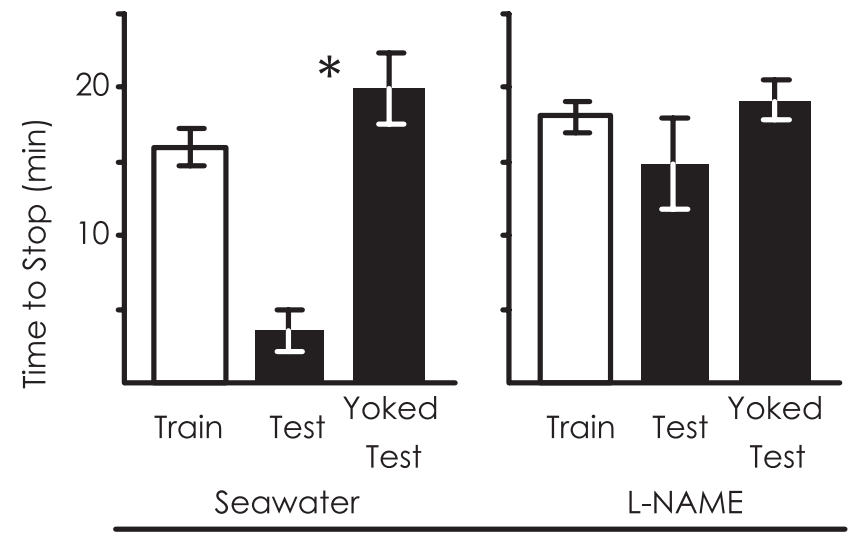

B) Time in the Mouth (first $5 \mathrm{~min}$ )
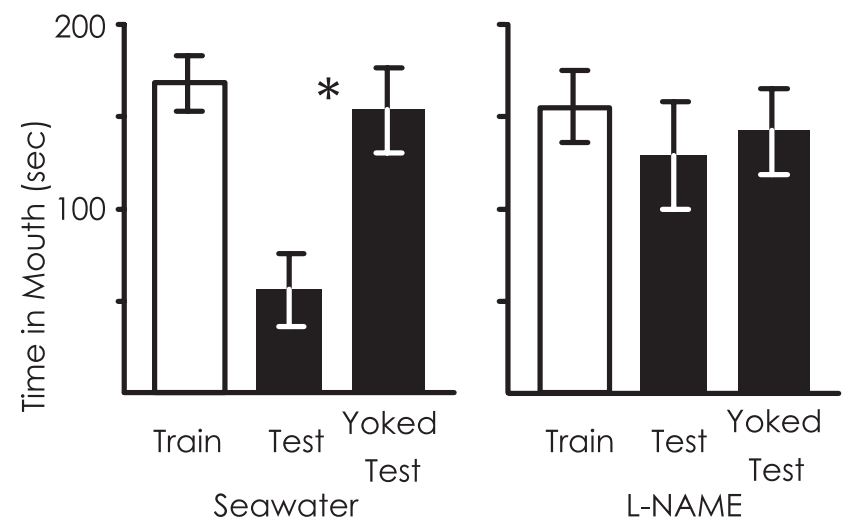

Figure 8. Lip stimulation alone is insufficient for memory formation. L-NAME-treated $(n=8)$ and seawater-treated $(n=7)$ animals were trained with inedible food. Each trained animal was yoked to an animal whose lips were stimulated (for L-NAME-treated, $n=8$; for seawatertreated, $n=7$ ) for a period equivalent to that of the training. Twenty-four hours later, both the trained and the yoked animals were tested with inedible netted food that entered the mouth and produced failed swallows. For animals treated with seawater, significant differences were observed between the animals that had been trained with food entering the mouth and those in which the lips were stimulated for both the time to stop responding to food $\left(p<0.001 ; t_{(13)}=5.68\right)$ and the time that food was in the mouth during the first 5 min of the test $\left(p<0.01 ; t_{(13)}=3.10\right.$; 2 -tailed $t$ tests). However, for animals treated with L-NAME, no significant differences were observed between the trained animals and the yoked controls (for the time to stop, $p=0.22, t_{(15)}=1.28$; for the time that food was in the mouth, $p=0.73, t_{(15)}=0.36 ; 2$-tailed $t$ tests).

\section{$D$-NAME does not block memory}

L-NAME blocks NO production by acting as a competitive inhibitor of L-arginine for NOS, the enzyme that produces NO. However, L-NAME may cause a number of additional, nonspecific effects (Buxton et al., 1993; Moroz et al., 1998). A number of experiments were designed to determine whether the effects of L-NAME occur via its inhibition of NO production or via nonspecific effects.

The first such experiment examined the effects of D-NAME, the chemically identical enantiomer of L-NAME, which does not interact with NOS and inhibit NO production. Animals (A. californica) were treated with D-NAME $10 \mathrm{~min}$ before the training. Memory was tested either 0.5 or $24 \mathrm{hr}$ after the training, to test the possible effects of D-NAME on short- and long-term memory, respectively. Because the previous experiment showing that short- and long-term memories are blocked by L-NAME were 


\section{A) Short-term Memory}

1) Time to Stop Responding

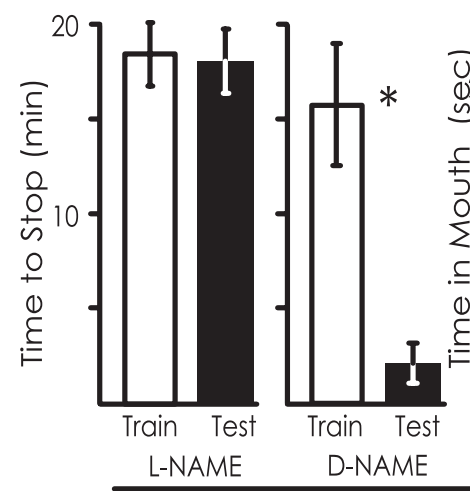

2) Time in the Mouth (first $5 \mathrm{~min}$ )

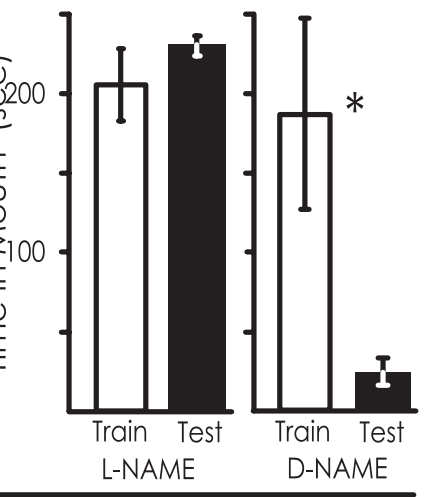

B) Long-term Memory

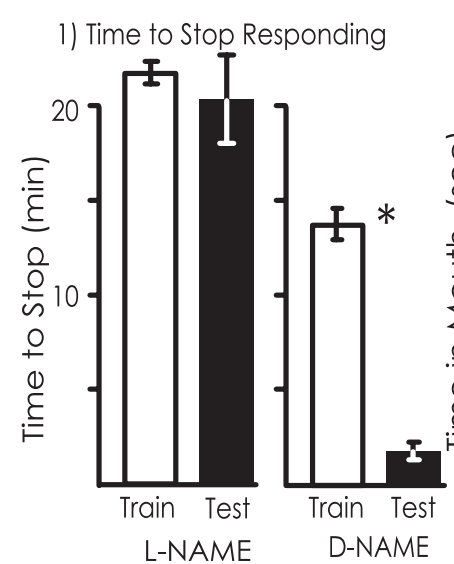

2) Time in the Mouth (first 5 min)

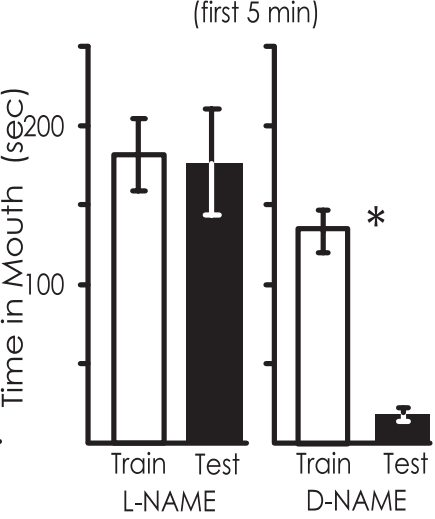

Figure 9. D-NAME does not block memory. $A$, Effects of L- and D-NAME application before training on short-term memory. L-NAME blocked short-term memory, as shown by no significant differences between training and testing (for the time to stop responding to food, $p=$ $0.53, t_{(9)}=0.69$; for the time that the food was in the mouth during the first 5 min, $p=0.21, t_{(9)}=1.49$; 2-tailed paired $t$ tests). In contrast, D-NAME did not affect short-term memory, as shown by significant savings between training and testing (for time to stop responding, $p<$ $0.001, t_{(7)}=9.73$; for time in the mouth, $p<0.001, t_{(7)}=7.97$; 2-tailed paired $t$ test). $B$, Effects of L- and D-NAME before training on long-term memory. L-NAME blocked long-term memory, as shown by no significant difference in the time to stop responding to food $\left(p=0.59 ; t_{(6)}=0.56\right)$ and in the time that the food was in the mouth during the first 5 min $(p=$ $0.88 ; t_{(6)}=0.15 ; 2$-tailed paired $t$ tests). In contrast, D-NAME did not affect long-term memory, because there were significant differences in both the time to stop responding to food $\left(p<0.001 ; t_{(6)}=17.28\right)$ and in the time in the mouth $\left(p<0.001 ; t_{(6)}=10.06 ; 2\right.$-tailed paired $t$ tests $)$. D-NAME-treated animals were run in a blind procedure with seawatertreated controls. There was no significant difference in the percentage of savings between D-NAME- and seawater-treated animals for the time to stop responding $\left(p=0.24 ; t_{(10)}=1.18\right)$, and for the time spent in the mouth, there was a significantly larger percentage of savings for D-NAME-treated animals than for seawater-treated animals $(p=0.4$; $t_{(10)}=2.42$; 2-tailed $t$ tests).

performed on $A$. fasciata, we also replicated these finding using $A$. californica, to be certain that L-NAME is also effective in this species.

As was found in previous experiments, no significant differences were seen between the initial training and the test in animals treated with L-NAME before the training, after either 0.5 or $24 \mathrm{hr}$, using either measure of memory (Fig. 9). In contrast, the animals treated with D-NAME showed significant savings when tested either 0.5 or $24 \mathrm{hr}$ after the training. D-NAME-treated animals were run along with controls treated with seawater (data not shown). The percentage of savings were significantly larger in D-NAME-treated animals than for animals treated with seawater for the time spent in the mouth $24 \mathrm{hr}$ after the training. There were no other significant differences between these D-NAMEand seawater-treated animals. Thus, D-NAME does not block either short- or long-memory, indicating that the effects of L-NAME are likely to be results of its specific actions on NOS.

\section{PTIO blocks long-term memory}

An additional way to demonstrate that the effects of L-NAME occur via inhibition of NO production would be to block NO activity by using another compound, which has a different mode of activity. Accordingly, we examined the effects on learning and long-term memory of PTIO, an NO scavenger (Park et al., 1998). Animals (A. californica) were treated with either PTIO or seawater $10 \mathrm{~min}$ before training, and memory was tested $24 \mathrm{hr}$ after training. The effects of PTIO were similar to those of L-NAME (Fig. 10). For animals treated with PTIO, there was no significant difference in the time to stop responding to food between the training and testing sessions, and there was also no significant difference in the time that food was in the mouth in the first $5 \mathrm{~min}$ of the training and test sessions. In contrast, control animals treated with seawater showed significant decreases in the time to stop responding to the food and in the time in the mouth during the first $5 \mathrm{~min}$. However, there were no significant differences in the percentage of savings between PTIO- and seawater-treated animals for either the time to stop responding or the time that food was in the mouth. Nonetheless, these data are consistent with the hypothesis that blocking NO signaling blocks memory formation.

\section{The NO donor SNAP restores long-term memory}

An additional way to demonstrate that L-NAME affects memory by blocking NO release is to show that memory can occur even in the presence of L-NAME if an exogenous source of NO is present. To examine whether exogenous NO can overcome the effects of L-NAME, the NO donor molecule SNAP (Park et al., 1998) was injected into animals (A. californica) immediately after L-NAME was injected. In control animals, seawater was injected in place of SNAP. Animals were then trained, and long-term memory was examined after $24 \mathrm{hr}$. Our expectation was that animals treated with SNAP would display long-term memory, whereas animals treated with seawater would not. This expectation was confirmed (Fig. 11). In animals treated with SNAP, there were significant differences between the initial training and the test $24 \mathrm{hr}$ after training, using as criteria both the time to stop responding and the time that food spent in the mouth for the first 5 min, whereas animals treated with seawater did not display memory, as measured by no significant changes between the training and the testing in the time to stop responding to the food or in the time spent in the mouth during the first $5 \mathrm{~min}$.

\section{Block of NO signaling also affects memory after spaced training}

A single training session continued until animals stop responding to food induces short-term memory, which is measured $0.5 \mathrm{hr}$ after training, and long-term memory is measured after $24 \mathrm{hr}$. However, from 1-12 hr after training, no memory is exhibited (Botzer et al., 1998). Intermediate-term memory that is measured $4 \mathrm{hr}$ after training can be elicited as a result of a spaced training procedure. 
PTIO

A) Time to Stop Responding

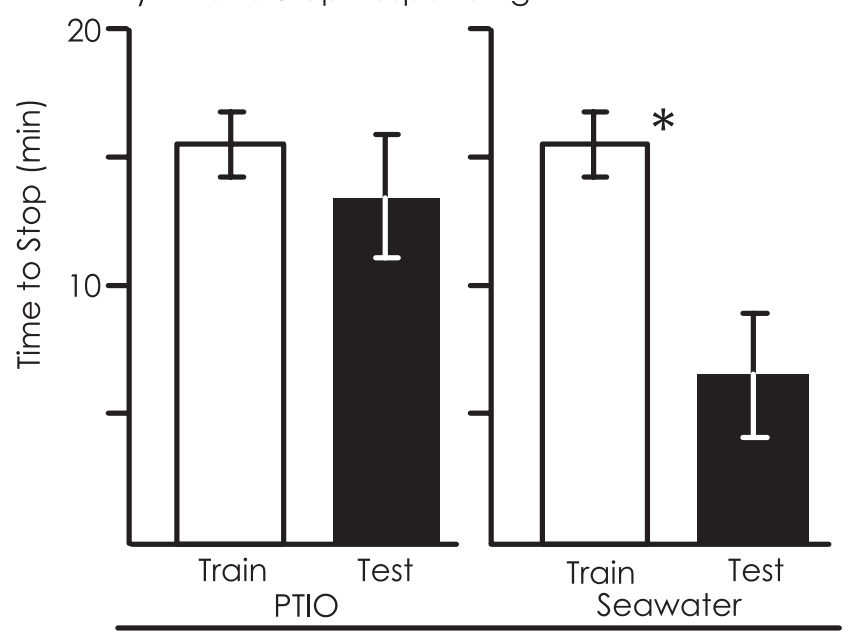

B) Time in the Mouth (first $5 \mathrm{~min}$ )

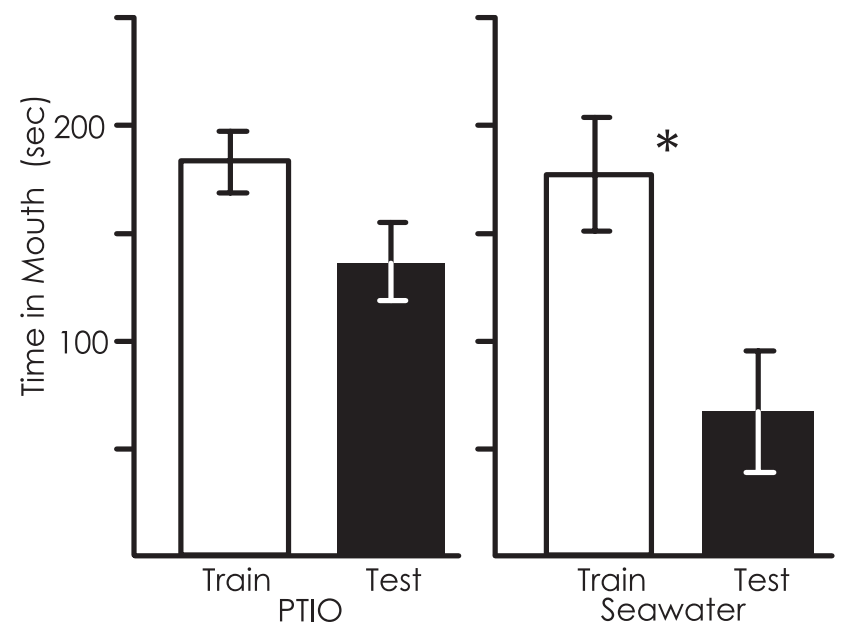

Figure 10. PTIO blocks long-term memory. Animals were treated with PTIO $(n=9)$ or seawater $(n=7)$ before training, and memory was measured after $24 \mathrm{hr}$. $A$, There was a significant decrease in the time to stop responding between the training and testing session for the control animals $\left(p=0.025 ; t_{(6)}=2.95\right)$ but not for animals treated with PTIO $\left(p=0.492 ; t_{(8)}=0.71 ; 2\right.$-tailed paired $t$ tests $)$. However, there was no significant difference in the percentage of change in response between the training and testing session between animals treated with PTIO and seawater $\left(p=0.09 ; t_{(13)}=1.82 ; 2\right.$-tailed $t$ test $) . B$, There was a significant decrease in the time that food was within the mouth during the first $5 \mathrm{~min}$ of a session between the training and testing session for the control animals $\left(p=0.016 ; t_{(6)}=3.33\right)$ but not for animals treated with PTIO ( $p=0.085 ; t_{(8)}=1.97 ; 2$-tailed paired $t$ tests). However, there was no significant difference in the percentage of change in response between PTIO- and seawater-treated animals between the training and testing session $\left(p=0.07 ; t_{(14)}=1.93 ; 2\right.$-tailed $t$ test $)$.

\section{L-NAME before training blocks intermediate-term memory}

The findings that L-NAME injected before training blocks shortand long-term memory raised the possibility that this procedure also blocks intermediate-term memory. This possibility was examined by treating animals (A. californica) with either L-NAME or seawater $10 \mathrm{~min}$ before the start of spaced training, which consisted of three short training sessions of $5 \mathrm{~min}$ each. The three sessions were separated by $0.5 \mathrm{hr}$ intervals. During these three intervals, the time that food spent in the mouth was measured. Four hours after the third session, the animals were tested by

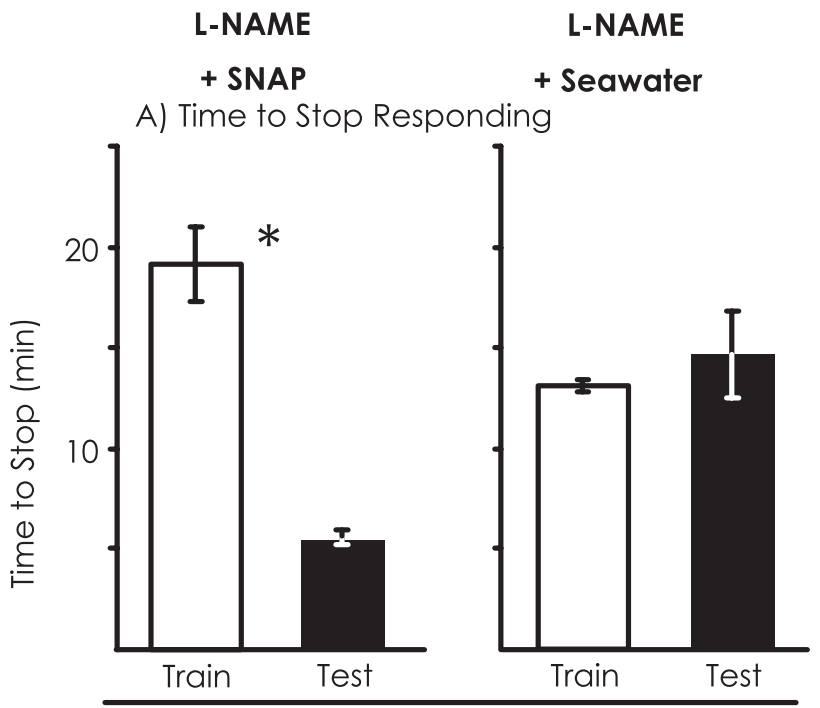

B) Time in the Mouth (first $5 \mathrm{~min}$ )
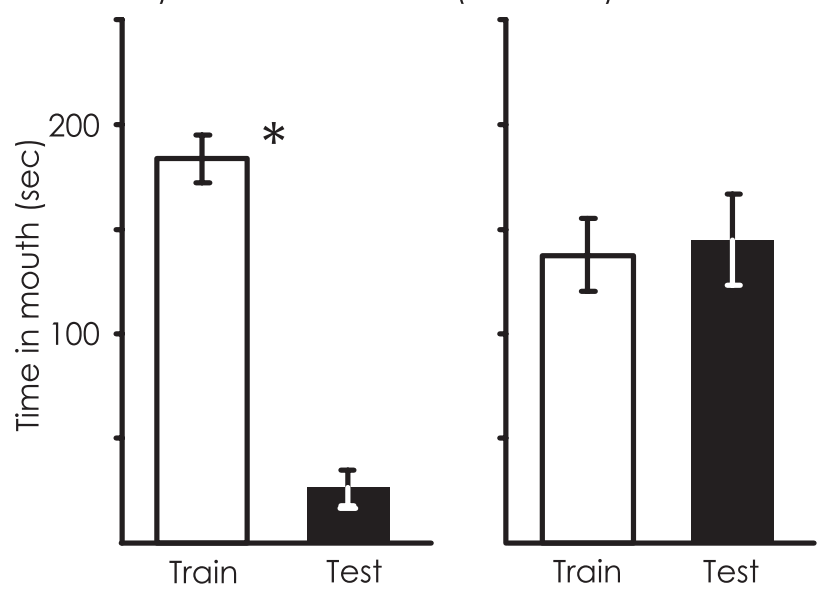

Figure 11. Effects on long-term memory of treating animals with the NO donor SNAP. All animals were treated with L-NAME before training. One group of animals $(n=8)$ was then immediately treated with SNAP, and another was treated with seawater $(n=5)$. Memory was examined after $24 \mathrm{hr}$. $A$, There was no significant decrease in the time to stop responding between the training and testing session for the animals treated with seawater $\left(p=0.85 ; t_{(4)}=0.20\right)$. In contrast, animals treated with SNAP displayed a decrease in the time to stop responding to food $\left(p=0.002 ; t_{(6)}=5.44 ; 2\right.$-tailed paired $t$ tests). There was also a significant difference between the animals receiving SNAP and seawater in the percentage of change in response $\left(p=0.005 ; t_{(11)}=3.44 ; 2\right.$-tailed $t$ test $)$. $B$, There was no significant decrease in the time that food was within the mouth during the first $5 \mathrm{~min}$ of a session between the training and testing session for the control animals $\left(p=0.50 ; t_{(4)}=0.75\right)$. However, animals treated with SNAP showed significant savings using this parameter $(p<$ $0.001 ; t_{(7)}=16.69 ; 2$-tailed paired $t$ tests). There was also a significant difference in the percentage of change in response between the animals receiving SNAP and seawater $\left(p=0.007 ; t_{(11)}=3.24 ; 2\right.$-tailed $t$ test $)$.

allowing them to attempt to eat inedible food until they stopped responding (Fig. 12).

In the control, seawater-treated animals, there was a progressive decrease in the time that food spent in the mouth over the three training sessions $\left(p<0.001 ; F_{(2,18)}=10.64\right)$. In contrast, there was no significant change in this parameter over the three sessions in animals that had been injected with L-NAME ( $p=$ $0.55 ; F_{(2,21)}=0.61$; one-way ANOVA) (Fig. 12A). These data suggest that the effects of the L-NAME treatment were still 


\section{A) Spaced Training}

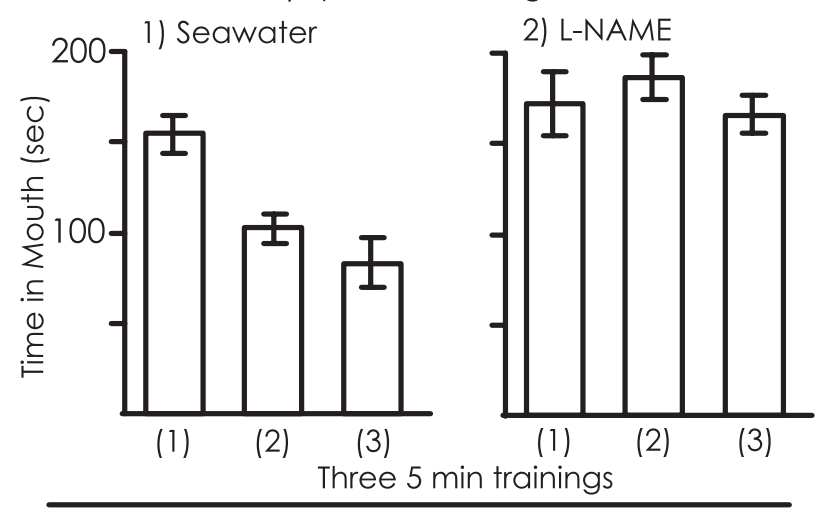

B) Intermediate-term Memory

1) Time to Stop

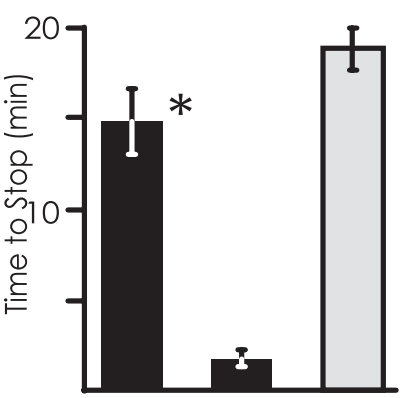

L-NAME Seawater Naive

C) Long - term Memory

1) Time to Stop

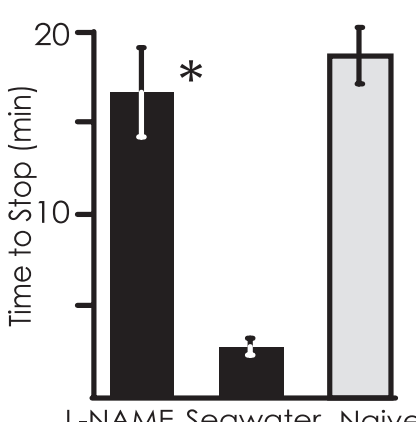

L-NAME Seawater Naive

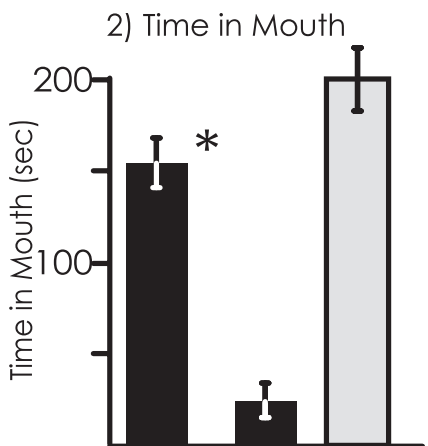

L-NAME Seawater Naive

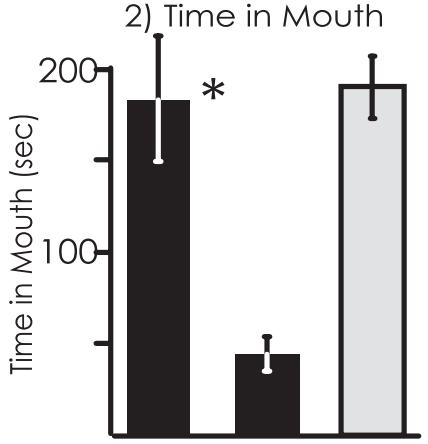

L-NAME Seawater Naive

Figure 12. Effects of L-NAME using spaced training. A, Animals were trained with three 5 min training sessions after being treated with artificial seawater $(n=7)$ or L-NAME $(n=8)$. For each of the three training sessions, the time that food was in the mouth was measured. Note that the data shown preceded the test of intermediate memory shown in $B$. Data on spaced training preceding long-term memory were similar to those shown (see Results). B, Four hours after spaced training, animals were retrained in a single session until they stopped responding to food. The three groups whose data are shown with shaded bars were tested in a blind procedure (for Naive; $n=7$ ). Animals treated with L-NAME showed no memory, whereas memory was seen in seawater-treated controls. $C$, In a separate population of animals that received spaced training, memory was examined $24 \mathrm{hr}$ after the training. Data on retention were gathered in a blind procedure, with $n=6$ naive animals. Animals treated with L-NAME $(n=6)$ showed no memory, whereas memory was seen in seawater-treated controls $(n=6)$.

present for $>1 \mathrm{hr}$ after the treatment, when animals received the third training session.

Four hours after the training (Fig. 12B), animals that had been treated with L-NAME displayed significant increases in respon-

siveness to food (time spent in mouth at the start of training, $p<$ $\left.0.001 ; t_{(14)}=7.45\right)$ and also took significantly longer to stop responding to the netted food (time to stop responding, $p<0.001$, $t_{(14)}=6.26$; two-tailed $t$ tests) than did animals that were treated with seawater. Values of animals treated with L-NAME were similar to those in naive, untreated animals. These data indicate that, in addition to blocking short- and long-term memories, L-NAME also blocks intermediate-term memory.

\section{L-NAME before training blocks long-term memory after spaced training}

Previous studies in the honeybee have shown that both massed and spaced training cause long-term memory processes, but these processes are separable by blocking NO signaling during training. Such a block specifically interferes with long-term memory after spaced training but not after massed training (Müller, 1996). The effects of spaced training on long-term memory after learning that a food is inedible in Aplysia have not been examined previously. To examine whether long-term memory after spaced training that food is inedible is also sensitive to L-NAME, animals ( $A$. fasciata) were trained as above with three 5 min training sessions. The sessions were separated by $0.5 \mathrm{hr}$. Memory was examined 24 hr after the training (Fig. 12C).

As in the above experiment, animals in which seawater was injected before spaced training displayed a progressive decrease in the time that food spent in the mouth over the three training sessions $\left(p<0.001 ; F_{(2,15)}=10.61\right)$. In contrast, there was no significant change in this parameter in animals that were treated with L-NAME $\left(p=0.42 ; F_{(2,15)}=0.98\right.$; one-way ANOVA; data not shown). Twenty-four hours after the training, there was a significant increase in the scores of the animals that had been treated with L-NAME with respect to the values observed in the seawater-treated animals (for the time to stop responding, $p<$ $0.001, t_{(10)}=5.82$; for time in the mouth, $p=0.002, t_{(10)}=4.15$; two-tailed $t$ tests). Values of animals treated with L-NAME were similar to those in naive, untrained animals. These data indicate that L-NAME blocks long-term memory after spaced training, as it does after a single training until the animals stop responding.

\section{L-NAME before training partially blocks very short-term memory}

Previous data (Botzer et al., 1998) have identified four separable memory processes after the training that food is inedible. The data above showed that three of these processes, short-, intermediate-, and long-term memories, are blocked by injecting L-NAME into Aplysia. It was of interest to examine whether the fourth form of memory, previously termed very short-term, is also affected. This memory is displayed during the initial training itself. When animals are trained with inedible food, their responses during the first 5 min of training are more vigorous than during the second $5 \mathrm{~min}$. However, allowing animals $15 \mathrm{~min}$ of rest after a 5 min training leads to a recovery of responsiveness. Thus, a 5 min training leads to a very short-term memory that decays within $15 \mathrm{~min}$. This memory can be assessed by comparing the responsiveness in successive periods during the initial training to stop responding to inedible food. To examine the effects of the very short-term memory, we examined the data on the initial training session in animals that were treated with either L-NAME or seawater. It is important to note that the time to stop responding is not significantly affected by L-NAME (Fig. $3 C$ ), and the responsiveness to food at the start of training is not affected by L-NAME (Fig, 3A,B). The present analysis was designed to 


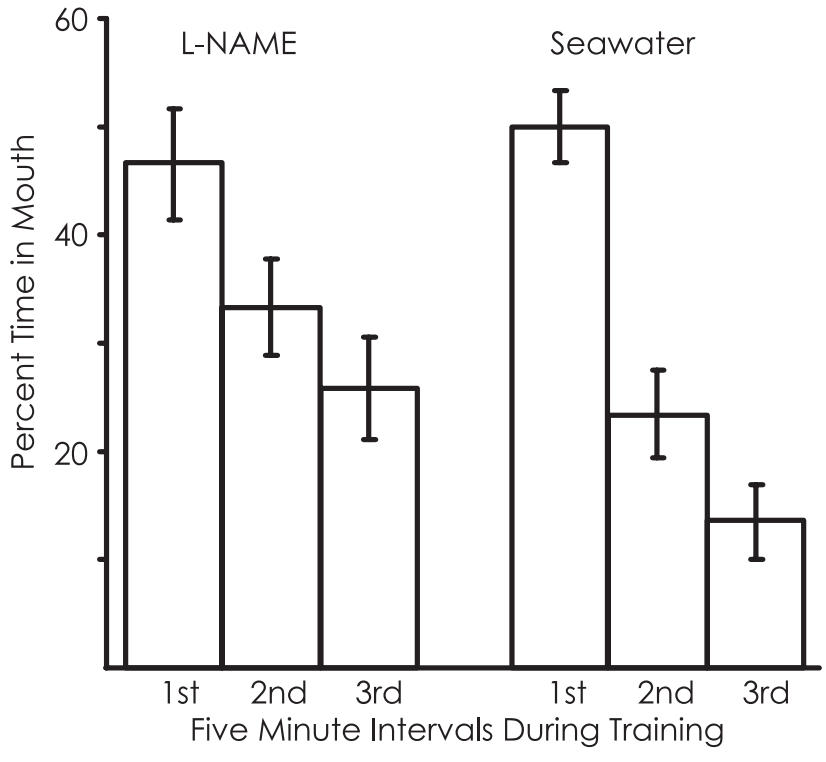

Figure 13. Effects of L-NAME on very short-term memory. Very shortterm memory was measured by comparing the percentage of time that food was spent in the mouth over three successive 5 min periods during the initial training. Normalized data were used in this experiment, because some animals (4 of 16 L-NAME-treated and 3 of 14 seawatertreated) reached the criterion to stop responding to the food before the end of the $15 \mathrm{~min}$. To compensate, the time that food was in the mouth during each 5 min period was normalized by dividing it by the total number of minutes that the animals responded to food during the $5 \mathrm{~min}$ period (the full 5 min for all animals during the first and second 5 min periods as well as for all animals that also responded throughout the third $5 \mathrm{~min}$ period; for animals that stopped during the last $5 \mathrm{~min}$ period, the time in the mouth was divided by the time during this period that had already gone by before the experiment was stopped).

determine whether animals treated with L-NAME are more responsive to food during the latter portion of a training session, despite a similar time to stop and despite similar responsiveness at the start of training.

In this analysis, for each animal (A. fasciata), the data were divided into $5 \mathrm{~min}$ intervals, and the percentage of the $5 \mathrm{~min}$ that food was in the mouth was calculated (Fig. 13). We then determined whether there was a significant change in the percentage of time spent in the mouth over the first three 5 min intervals, whether there were significant differences between L-NAME- and seawater-treated animals, and whether there was a significant interaction between these variables.

There was a significant decrease in the responsiveness of the animals over the training period, as measured by the percentage of time that food was in the mouth $\left(p<0.001 ; F_{(1,26)}=141.57\right)$. There was also a significant difference between animals treated with L-NAME and with seawater $\left(p<0.001 ; F_{(1,26)}=156.68\right)$. There was also a significant interaction between these variables $\left(p=0.001 ; F_{(1,26)}=14.87\right.$; two-way ANOVA with repeated measures).

The data above indicated that animals treated with L-NAME are more responsive than are animals treated with seawater during the latter portion of the training. To quantify this difference, the time that food was in the mouth was calculated for all animals from the period 5-15 min after the start of training. For animals treated with L-NAME, food was in the mouth for $28.6 \%$ (SD, 16.9\%) of the time, whereas for seawater-treated animals, food was in the mouth for $16.6 \%$ (SD, $11.3 \%$ ) of the time ( $p=$ $0.03 ; t_{(28)}=2.26$; two-tailed $t$ test $)$. These data confirm that animals treated with L-NAME are more responsive to food in the latter portion of training than are the seawater-treated controls. This finding is consistent with the idea that the decrease in responses during the latter part of training represents a form of very short-term memory, and this memory is affected by L-NAME. It is important to note that L-NAME did not completely block the very short-term memory but, rather, significantly weakened it, as shown by the significant interaction between the treatments and the successive periods and by the fact that the response of L-NAME-treated animals did decrease during the training. Thus, some component of very short-term memory is not dependent on a process blocked by L-NAME.

\section{DISCUSSION}

Treatment with L-NAME before training that food is inedible but not after training blocked the expression of short-, intermediate-, and long-term memories and also attenuated very short-term memory without completely blocking it. L-NAME had little effect on feeding behavior per se or on the initial training. Thus, L-NAME does not cause pervasive modulation or poisoning of feeding and other behaviors. L-NAME interfered with memory because it is a competitive inhibitor of L-arginine, a substrate of Nitric Oxide Synthase (NOS). Treatment with D-NAME, the enantiomer of L-NAME that does not interact with NOS, did not affect short-term or long-term memory. In addition, long-term memory was blocked by PTIO, an NO scavenger. Finally, longterm memory was restored in L-NAME treated animals by SNAP, a releaser of NO.

\section{Timing of NO modulation}

Inedible netted foods elicit a mixture of feeding movements. It is unlikely that memory formation depends on NO release contingent to a particular type of movement or to a particular time during training, because SNAP would cause an increase in NO throughout training. NO is unlikely to function as a reinforcer that must be timed to the success or failure of a particular bite or a swallow and is likely to function as a modulator allowing reinforcing stimuli to be effective.

\section{Different effects of NO blocking and gut denervation}

Aplysia feeding is initiated, organized, and effected by circuitry within the buccal and cerebral ganglia (Kupfermann, 1974), which contain few NOS-containing somata but contain many NOSpositive neurites (Jacklet and Gruhn, 1994; Meulemans et al., 1995; Moroz, 2000; Jacklet and Koh, 2001). Some neurites may be processes of peripheral neurons, perhaps from lip chemoreceptors, which are NOS-positive in other gastropods (Elphick et al., 1995; Moroz, 2000), or from the gut, which contains many peripheral neurons (Schwarz and Susswein, 1986). If the block of memory arising from blocking NO has its origin in the block of transmission from the gut, denervating the gut and blocking NO should have similar effects.

Gut denervation (Schwarz and Susswein, 1986) and blocking of NO signaling (Fig. 6) are similar in that both interfere with long-term memory when performed before training but not after (Schwarz et al., 1991) (Fig. 7). However, gut denervation and NO blocking differ in their effects on the initial learning. Gut denervation blocks the initial learning, as shown by a lengthened training session, with little decrease in responsiveness before animals stop responding. This pattern is explained by sensory adaptation or habituation arising from sustained lip stimulation (Schwarz and Susswein, 1986). These studies suggested that gut 
stimuli provide reinforcement for learning (Schwarz and Susswein, 1986). This suggestion was strengthened by evidence that electrical stimulation of the esophageal nerves innervating the gut is a reinforcer in a neural analog of learning (Nargeot et al., 1997) and in feeding of intact animals (Brembs et al., 2002). In contrast, blocking of NO signaling causes no change in the time to stop responding and maintains the graded decrease in feeding responses (although the decrease is less pronounced) (Fig. 13). These differences suggest that blocking of NO and gut denervation affect learning and memory via different pathways and are consistent with the suggestion above that block of NO does not block reinforcement. However, we cannot eliminate the possibility that cutting the esophageal nerve interrupts axons in addition to those using NO as a transmitter, and the additional neurons account for the behavioral differences.

\section{Different effects of NO blocking and isolation}

Isolation from conspecifics also affects learning and memory that food is inedible in A. fasciata (Schwarz and Susswein, 1992; Schwarz et al., 1998). Isolation affects many aspects of feeding and other behaviors (Blumberg and Susswein, 1998; Blumberg et al., 1998) in a manner suggesting that isolation is a stressful stimulus in Aplysia (Schwarz et al., 1998), as it is in other animals (Boissy and Le Neindre, 1997). Stress can modulate learning and memory (Schacter, 1996), and it has been proposed that the effects of isolation on learning that a food is inedible are explained by such modulation (Schwarz et al., 1998). The behavioral effects of NO blocking and isolation are very different, indicating that these treatments operate via different mechanisms. First, L-NAME causes minimal effects on feeding per se (Figs. 1 and 2). Second, training isolated animals causes rapid cessation of feeding, with food not often entering the mouth (Schwarz and Susswein, 1992), whereas NO blocking does not affect the time to stop feeding (Fig. 3) and moderately augments the time in the mouth (Fig. 13). Third, isolation subsequent to training is also effective in blocking long-term memory formation (Schwarz et al., 1998), whereas NO blocking after training is not (Figs. 5, 7). Finally, isolation during training blocks only long-term memory, sparing short-term memory (Haba, 2001), whereas NO blocking affects both long- and short-term memories (Figs. 4, 6).

\section{Localization of different memory mechanisms}

Previous studies have indicated that short- and long-term memory are parallel processes, because each can be established independent of the other (Botzer et al., 1998). Parallel memory processes could result from changes at different sites within the nervous system or from different molecular events at a single neural site. In memory affecting the gill and tail withdrawal reflexes of Aplysia, different memory processes are localized at the same synapses but are effected via different intracellular mechanisms, which are nonetheless initiated by a common neurotransmitter, serotonin (Squire and Kandel, 1999; Sutton and Carew, 2000; Sutton et al., 2001). The finding that blocking NO affects multiple memory stages after training with inedible food suggests that the multiple stages of memory in this system may also arise at a common site, because relatively few neurons in the buccal and cerebral ganglia use NO as a transmitter (Jacklet and Gruhn, 1994; Jacklet and Koh, 2001). However, we cannot eliminate the possibility that different memory processes are localized to different neurons in the small group of NOS-positive neurons or perhaps to different target neurons of a common presynaptic NOS-positive cell.

In Aplysia (Mothet et al., 1996; Koh and Jacklet, 1999; Lewin and Walters, 1999) and in other organisms (Garthwaite and Boulton, 1995), NO generally acts by activating guanylyl cyclase and thereby increasing intracellular cGMP. cGMP in turn activates cGMP-dependent protein kinase (PKG), which phosphorylates proteins, and thereby contributes to short-term modulation. The PKG system may also regulate gene expression (Lewin and Walters, 1999) or can interact with other kinase systems that respond to other second messengers (e.g., the cAMP-dependent kinases and phosphodiesterases), which can regulate gene transcription or translation, and thereby affect longer-term memory processes (Squire and Kandel, 1999). In other learning tasks in Aplysia, a common second messenger, cAMP, has a role in both short- and long-term memory (Squire and Kandel, 1999). Our data suggest that cGMP could act in a parallel manner in learning that a food is inedible. In contrast, in other organisms, NO plays a role only in a specific memory stage (Müller, 1996).

\section{Possible involvement of C2}

Another explanation for the involvement of NO in many memory stages is that NO is a transmitter of a key neuron involved in memory formation, such as C2 (Jacklet, 1995). C2 releases two transmitters, histamine and NO (McCaman and Weinreich, 1985; Weiss et al., 1986a; Chiel et al., 1990; Koh and Jacklet, 1999). Both produce slow EPSPs and increased firing in the serotonergic metacerebral cell (MCC) (Koh and Jacklet, 1999). The MCC in turn modulates many neurons and muscles (Kupfermann et al., 1991). C2 is a sensory neuron responding to mechanical stimuli in the perioral zone (Weiss et al., 1986b). Entry of food into the mouth and failed swallows such as those occurring in training with inedible food are likely to activate C2 strongly. Entry of food into the mouth is an essential component of learning and memory that food is inedible (Fig. 8) (Schwarz et al., 1988). Blocking NO release from $\mathrm{C} 2$ could be equivalent to attenuating the signal that food has entered the mouth during training. This attenuation is likely to result in a decrease in the $\mathrm{MCC}$ response to $\mathrm{C} 2$ and a decrease in the serotonergic modulation of feeding during the training. Such a decrease may contribute to or account for the block of memory.

\section{NO in other memory tasks}

The role of NO in memory that a food is inedible is consistent with previous work. NO plays a role in long-term potentiation in the mammalian hippocampus (Hawkins et al., 1998) and longterm depression in the cerebellum (Ito, 2001), processes thought to be neural correlates of various forms of declarative and motor learning, respectively (Squire and Kandel, 1999). NO has been implicated in avoidance learning in chicks (Hölscher and Rose, 1993; Rickard et al., 1999), in imprinting and odor learning in lambs (Kendrick et al., 1997), and in other forms of olfactory learning (Samama and Boehm, 1999). In invertebrates, NO has a role in the formation of long-term memory after conditioning of proboscis extension in the honeybee (Müller, 1996), tactile learning in the octopus (Robertson et al., 1994, 1995), and food attraction conditioning in Helix (Teyke, 1996). It also has a role in memory consolidation after appetitive conditioning in Lymnaea (Kemenes et al., 2002). In Aplysia, NO signaling plays a role in long-term hyperexcitability caused by tissue damage (Lewin and Walters, 1999). Examining the role of NO in learning and memory affecting Aplysia feeding has an advantage over many other systems, because the relationship between biochemical processes in specific neurons and the function of these neurons within a circuit can be studied, allowing us to relate biochemical events in individual cells to changes in behavior. 


\section{REFERENCES}

Blumberg S, Susswein AJ (1998) Consummatory feeding movements in Aplysia fasciata are facilitated by conspecifics with access to mates, by reproductive tract homogenates and by bag cell peptides. J Comp Physiol [A] 182:175-182.

Blumberg S, Haran T, Botzer D, Susswein AJ, Teyke T (1998) Pheromones linked to sexual behaviors excite the appetitive phase of feeding behavior in Aplysia fasciata. I. Modulation and excitation of appetitive behaviors. J Comp Physiol [A] 182:777-783.

Böhme GA, Bon C, Lemaire M, Reibaud M, Piot O, Stutzmann JM, Doble A, Blanchard JC (1993) Altered synaptic plasticity and memory formation in nitric oxide synthase inhibitor-treated rats. Proc Natl Acad Sci USA 90:9191-9194.

Boissy A, Le Neindre P (1997) Behavioral cardiac and cortisol responses to brief peer separation and reunion in cattle. Physiol Behav 61:693-699.

Botzer D, Markovich S, Susswein AJ (1998) Multiple memory processes following training that a food is inedible in Aplysia. Learn Mem 5:204-219.

Brembs B, Lorenzetti FD, Reyes FD, Baxter DA, Byrne JH (2002) Operant reward learning in Aplysia: neuronal correlates and mechanisms. Science 296:1706-1709.

Buxton ILO, Cheek DJ, Eckman D, Westfall DP, Sanders KM, Keef KD (1993) NG-nitro L-arginine methyl ester and other alkyl esters or arginine are muscarinic receptor antagonists. Circ Res 72:387-395.

Chiel HJ, Weiss KR, Kupfermann I (1990) Multiple roles of a histaminergic afferent neuron in the feeding behavior of Aplysia. Trends Neurosci 13:223-237.

Elphick MR, Kemenes G, Staras K, O'Shea M (1995) Behavioral role for nitric oxide in chemosensory activation of feeding in a mollusc. J Neurosci 15:7653-7664

Garthwaite J, Boulton CL (1995) Nitric-oxide signaling in the centralnervous-system. Annu Rev Physiol 57:683-706.

Haba D (2001) The effect of three variables (food, isolation and change of partners) on learning and memory in Aplysia. MSc thesis, Bar Ilan University.

Hawkins RD, Son H, Arancio O (1998) Nitric oxide as a retrograde messenger during long-term potentiation in hippocampus. Prog Brain Res 118:155-172.

Hölscher C, Rose SPR (1993) Inhibiting synthesis of the putative retrograde messenger nitric oxide results in amnesia in a passive avoidance task in the chick. Brain Res 619:189-194.

Horn CC, Geizhals CR, Kupfermann I (2001) Further studies of bulk and orosensory decrement in producing satiation of feeding in Aplysia. Brain Res 918:51-59.

Hurwitz I, Susswein AJ (1996) B64, a newly-identified central pattern generator element producing a phase switch from protraction to retraction in buccal motor programs of Aplysia californica. J Neurophysiol 75:1327-1344.

Hurwitz I, Kupfermann I, Susswein AJ (1997) Different roles of neurons B63 and B34 that are active during the protraction phase of buccal motor programs in Aplysia californica. J Neurophysiol 78:1305-1319.

Ito M (2001) Cerebellar long-term depression: Characterization signal transduction and functional roles. Physiol Rev 81:1143-1195.

Jacklet JW (1995) Nitric oxide is used as an orthograde cotransmitter at identified histaminergic synapses. J Neurophysiol 74:891-895.

Jacklet JW (1997) Nitric oxide signaling in invertebrates. Invertebr Neurosci 3:1-14.

Jacklet JW, Gruhn M (1994) Co-localization of NADPH-diaphorase and myomodulin in synaptic glomeruli of Aplysia. NeuroReport $5: 1841-1844$

Jacklet JW, Koh H-Y (2001) Nitric oxide as an orthograde cotransmitter at central synapses of Aplysia: responses of isolated neurons in culture. Am Zool 41:282-291

Kemenes I, Kemenes G, Andrew RJ, Benjamin PR, O'Shea M (2002) Critical time-window for NO-cGMP-dependent long-term memory formation after one-trial appetitive conditioning. J Neurosci 22:1414-1425.

Kendrick KM, Guevara-Guzman R, Zorrilla J, Hinton MR, Broad KD, Mimmack M, Ohkura S (1997) Formation of olfactory memories mediated by nitric oxide. Nature 388:670-674.

Koh H-Y, Jacklet JW (1999) Nitric oxide stimulates cGMP production and mimics synaptic responses in metacerebral neurons of Aplysia. J Neurosci 19:3618-3626.

Korneev SA, Kemenes I, Straub V, Staras K, Korneeva EI, Kemenes G, Benjamin PR, O'Shea M (2002) Suppression of nitric oxide (NO)dependent behavior by double-stranded RNA-mediated silencing of a neuronal NO synthase gene. J Neurosci 22:RC227(1-5).

Kupfermann I (1968) A circadian locomotor rhythm in Aplysia californica. Physiol Behav 3:179-181.

Kupfermann I (1974) Dissociation of appetitive and consummatory phases of feeding in Aplysia: a lesion study. Behav Biol 10:89-97.

Kupfermann I, Teyke T, Rosen SC, Weiss KR (1991) Studies of behavioral state in Aplysia. Biol Bull 180:262-268.

Lechner HA, Baxter DA, Byrne JH (2000) Classical conditioning of feeding in Aplysia: I. Behavioral analysis. J Neurosci 20:3369-3376.
Lewin MR, Walters ET (1999) Cyclic GMP pathway is critical for inducing long-term sensitization of nociceptive sensory neurons. Nat Neurosci 2:18-23.

McCaman RE, Weinreich D (1985) Histaminergic synaptic transmission in the cerebral ganglion of Aplysia. J Neurophysiol 53:1016-1037.

Meulemans A, Mothet JP, Schirar A, Fossier P, Tauc L, Baux G (1995) A nitric oxide synthase activity is involved in the modulation of acetylcholine release in Aplysia ganglion neurons: a histological voltammetric and electrophysiological study. Neuroscience 69:985-995.

Moroz LL (2000) Giant identified NO-releasing neurons and comparative histochemistry of putative nitrergic systems in gastropod molluscs. Microsc Res Tech 49:557-569.

Moroz LL, Norby SW, Cruz L, Sweedler JV, Gillette R, Clarkson RB (1998) Non-enzymatic production of nitric oxide (NO) from NO synthase inhibitors. Biochem Biophys Res Commun 253:571-576.

Morton DW, Chiel HJ (1993) The timing of activity in motor neurons that produce radula movements distinguishes ingestion from rejection in Aplysia. J Comp Physiol [A] 173:519-536.

Mothet JP, Fossier P, Tauc L, Baux G (1996) Opposite actions of nitric oxide on cholinergic synapses: which pathways? Proc Natl Acad Sci USA 93:8721-8726.

Müller U (1996) Inhibition of nitric oxide synthase impairs a distinct form of long-term memory in the honeybee Apis mellifera. Neuron 16:541-549.

Nargeot R, Baxter DA, Byrne JH (1997) Contingent-dependent enhancement of rhythmic motor patterns: an in vitro analog of operant conditioning. J Neurosci 17:8093-8105.

Park J-H, Straub VA, O'Shea M (1998) Anterograde signaling by nitric oxide: characterization and in vitro reconstitution of an identified nitrergic synapse. J Neurosci 18:5463-5476.

Plummer MR, Kirk MD (1990) Premotor neuron-B51 and neuron-B52 in the buccal ganglia of Aplysia californica: synaptic connections effects on ongoing motor rhythms and peptide modulation. J Neurophysiol 63:539-558

Rickard NS, Gibbs ME, Ng KT (1999) Inhibition of the endothelial isoform of nitric oxide synthase impairs long-term memory formation in the chick. Learn Mem 6:458-466.

Robertson JD, Bonaventura J, Kohm AP (1994) Nitric Oxide is required for tactile learning in Octopus vulgaris. Proc R Soc Lond B Biol Sci 256:269-273.

Robertson JD, Bonaventura J, Kohm A (1995) Nitric oxide synthase inhibition blocks octopus touch learning without producing sensory or motor dysfunction. Proc R Soc Lond B Biol Sci 261:167-172.

Rosen SC, Weiss KR, Kupfermann I (1982) Cross-modality sensory integration in the control of feeding Aplysia. Behav Neural Biol 35:56-63.

Rosen SC, Weiss KR, Goldstein RS, Kupfermann I (1989) The role of a modulatory neuron in feeding and satiation in Aplysia: effects of lesioning of the serotonergic metacerebral cells. J Neurosci 9:1562-1578.

Rosen SC, Teyke T, Miller MW, Weiss KR, Kupfermann I (1991) Identification and characterization of cerebral-to-buccal interneurons implicated in the control of motor programs associated with feeding in Aplysia. J Neurosci 11:3630-3655.

Samama B, Boehm N (1999) Inhibition of nitric oxide synthase impairs early olfactory associative learning in newborn rats. Neurobiol Learn Mem 71:219-231.

Schacter DL (1996) Searching for memory. New York: Basic.

Schwarz M, Susswein AJ (1986) Identification of the neural pathway for reinforcement of feeding when Aplysia learn that food is inedible. J Neurosci 6:1528-1536.

Schwarz M, Susswein AJ (1992) Presence of conspecifics facilitates learning that food is inedible in Aplysia fasciata. Behav Neurosci 106:250-261

Schwarz M, Markovich S, Susswein AJ (1988) Parametric features of inhibition of feeding in Aplysia by associative learning satiation and sustained lip stimulation. Behav Neurosci 102:124-133.

Schwarz M, Feldman E, Susswein AJ (1991) Variables affecting longterm memory of learning that a food is inedible in Aplysia. Behav Neurosci 105:193-201.

Schwarz M, Blumberg S, Susswein AJ (1998) Social isolation blocks the expression of memory following training that a food is inedible in Aplysia fasciata. Behav Neurosci 112:942-951.

Squire LR, Kandel ER (1999) . Memory: from mind to molecules. San Francisco: Freeman.

Susswein AJ, Byrne JH (1988) Identification and characterization of neurons initiating patterned neural activity in the buccal ganglia of Aplysia. J Neurosci 8:2049-2061.

Susswein AJ, Kupfermann I, Weiss KR (1976) The stimulus control of biting in Aplysia. J Comp Physiol 108:75-96.

Susswein AJ, Weiss KR, Kupfermann I (1978) Effects of food arousal on latency of biting in Aplysia. J Comp Physiol 123:31-41.

Susswein AJ, Schwarz M, Feldman E (1986) Learned changes of feeding behavior in Aplysia in response to edible and inedible foods. J Neurosci 6:1513-1527.

Susswein AJ, Hurwitz I, Thorne R, Byrne JH, Baxter DA (2002) Mech- 
anisms underlying fictive feeding in Aplysia: coupling between a large neuron with plateau potentials activity and a spiking neuron. J Neurophysiol 87:2307-2323.

Sutton MA, Carew TJ (2000) Parallel molecular pathways mediate expression of distinct forms of intermediate-term facilitation at tail sensory-motor synapses in Aplysia. Neuron 26:219-231.

Sutton MA, Masters SE, Bagnall MW, Carew TJ (2001) Molecular mechanisms underlying a unique intermediate phase of memory in Aplysia. Neuron 31:143-154.

Teyke T (1996) Nitric oxide but not serotonin is involved in acquisition of food-attraction conditioning in the snail Helix pomatia. Neurosci Lett 206:29-32.

Teyke T, Weiss KR, Kupfermann I (1990) An identified neuron (CPR) evokes neuronal responses reflecting food arousal in Aplysia. Science 247:85-87.

Teyke T, Rosen SR, Weiss KR, Kupfermann I (1993) Dopaminergic neuron B20 generates rhythmic neuronal activity in the feeding motor circuitry of Aplysia. Brain Res 630:226-237.

Weiss KR, Chiel HJ, Koch U, Kupfermann I (1986a) Activity of an identified histaminergic neuron and its possible role in arousal of feeding behavior in semi-intact Aplysia. J Neurosci 6:2403-2415.

Weiss KR, Chiel HJ, Kupfermann I (1986b) Sensory function and gating of histaminergic neuron C2 in Aplysia. J Neurosci 6:2416-2424.

Ziv I, Lustig C, Markovich S, Susswein AJ (1991) Sequencing of behaviors in Aplysia fasciata: Integration of feeding reproduction and locomotion. Behav Neural Biol 56:148-169. 